\title{
In Vivo Imaging of Preferential Motor Axon Outgrowth to and Synaptogenesis at Prepatterned Acetylcholine Receptor Clusters in Embryonic Zebrafish Skeletal Muscle
}

\author{
Jessica A. Panzer,* Yuanquan Song, * and Rita J. Balice-Gordon \\ Department of Neuroscience, University of Pennsylvania School of Medicine, Philadelphia, Pennsylvania 19104
}

\begin{abstract}
Little is known about the spatial and temporal dynamics of presynaptic and postsynaptic specializations that culminate in synaptogenesis. Here, we imaged presynaptic vesicle clusters in motor axons and postsynaptic acetylcholine receptor (AChR) clusters in embryonic zebrafish to study the earliest events in synaptogenesis in vivo. Prepatterned AChR clusters are present on muscle fibers in advance of motor axon outgrowth from the spinal cord. Motor axon growth cones and filopodia are selectively extended toward and contact prepatterned AChR clusters, followed by the rapid clustering of presynaptic vesicles and insertion of additional AChRs, hallmarks of synaptogenesis. All initially formed neuromuscular synapses contain AChRs that were inserted into the membrane at the time the prepattern is present. Examination of embryos in which AChRs were blocked or clustering is absent showed that neither receptor activity or receptor protein is required for these events to occur. Thus, during initial synaptogenesis, postsynaptic differentiation precedes presynaptic differentiation, and prepatterned neurotransmitter clusters mark sites destined for synapse formation.
\end{abstract}

Key words: filopodia; motor neuron; axon guidance; acetylcholine receptor; neuromuscular junction; growth cone

\section{Introduction}

Neuronal circuitry becomes wired during development via mechanisms that direct axons to make synaptic connections with appropriate postsynaptic targets. However, the spatial and temporal dynamics of these events are poorly understood. Some studies have suggested that presynaptic differentiation precedes and initiates postsynaptic differentiation (Rao et al., 1998; Friedman et al., 2000; Okabe et al., 2001; Washbourne et al., 2002), whereas others have suggested that the opposite occurs (Cooper et al., 1992; Saito et al., 1992). These questions remain unresolved in large part because, to date, few studies have simultaneously imaged both presynaptic terminals and postsynaptic specializations in vivo (Javaherian and Cline, 2005), and none has examined the dynamism of both presynaptic and postsynaptic specializations simultaneously in living animals over time.

Neuromuscular synapses between motor neurons and muscle fibers have been used for studies of synaptogenesis in several invertebrate and vertebrate species (Sanes and Lichtman, 1999; Jin, 2002; Goda and Davis, 2003). Over the last two decades, studies of neuromuscular synaptogenesis in rodents, amphibi-

Received Aug. 29, 2005; revised Nov. 30, 2005; accepted Dec. 2, 2005.

This work was supported by National Institutes of Health Grants NS45919 and NS50524 (R.J.B.-G.) and a Howard Hughes Medical Institute predoctoral fellowship (J.A.P.). We thank A. Kugath, M. Scott, and H.-Y. Zhou for technical assistance, Dr. P. Brehm for providing heterozygous carriers of the sofa potato mutation, Dr. S. Smith for providing the UAS-VAMP-GFP construct, and Dr. S. Gibbs for helpful discussions.

*J.A.P. and Y.S. contributed equally to this work.

Correspondence should be addressed to Rita J. Balice-Gordon, Department of Neuroscience, University of Pennsylvania School of Medicine, 423 Johnson Pavilion, 3600 Hamilton Walk, Philadelphia, PA 19104. E-mail: rbaliceg@mail.med.upenn.edu.

DOI:10.1523/JNEUROSCI.3656-05.2006

Copyright $\odot 2006$ Society for Neuroscience $\quad$ 0270-6474/06/260934-14\$15.00/0 ans, and fish have suggested that the clustering of postsynaptic acetylcholine receptors (AChRs) is induced by motor axon contact with muscle fibers by presynaptic release of the proteoglycan agrin and signaling through the tyrosine kinase receptor, musclespecific kinase (MuSK), in the muscle fiber membrane (Sanes and Lichtman, 1999). In contrast, work in nerve-muscle cocultures has shown that small, nonsynaptic AChR clusters are present in the absence of neurite contact. These clusters, however, are not targeted for innervation but were dispersed, and receptors clustered de novo at sites of neurite contact with muscle fiber membranes (Fischbach and Cohen, 1973; Sytkowski et al., 1973; Anderson and Cohen, 1977; Frank and Fischbach, 1979; Bloch, 1988).

More recently, observations made in rodents during early stages of synaptogenesis and in mutant mice lacking motor neurons showed that, before and in the absence of innervation, $\mathrm{AChR}$ clusters are present on central region of muscle fibers (endplate band) through which the ingrowing nerve normally extends (Harris, 1981; Lupa and Hall, 1989; Morris et al., 1999; Feng et al., 2000; Yang et al., 2000; Lin et al., 2001) (for review, see Arber et al., 2002). We recently showed that AChR clusters are present in myotomal muscle of zebrafish, well before motor axons extend from the spinal cord (Panzer et al., 2005) (see also Flanagan-Steet et al., 2005). Thus, postsynaptic specializations are prepatterned in vertebrate muscles well in advance of innervation. Contrary to the prevailing belief that $\mathrm{AChR}$ clustering was dependent on the activation of MuSK via agrin released from motor axon growth cones (Sanes and Lichtman, 1999), in mice, prepatterned AChR clusters are formed in an agrin-independent, although MuSKdependent manner (Lin et al., 2001; Yang et al., 2001). Similarly, nonsynaptic neurotransmitter receptor clusters are present on 
the dendrites and soma of CNS neurons before axon contact both in vivo and in vitro (Aoki et al., 1994; Rao et al., 1998; Washbourne et al., 2002). However, the fate of prepatterned neurotransmitter receptor clusters and their role in subsequent synaptogenesis remain poorly understood.

Here, we report observations made using in vivo imaging of the spatial and temporal dynamics of motor axon growth cones and nascent terminals, and of the fate of prepatterned AChR clusters in zebrafish embryos. The optical transparency and rapid development of zebrafish embryos facilitate studies of neuromuscular synaptogenesis at developmental stages that are inaccessible in mammals. These observations show that motor axon growth cones preferentially contact prepatterned AChR clusters and form synapses at those sites. Thus, prepatterning of postsynaptic targets determines the spatial location of initial synaptogenesis in muscle, and may play a similar role during synaptogenesis in the CNS.

\section{Materials and Methods}

Zebrafish strains. Wild-type, HuC:GFP (Park et al., 2000), and sofa potato (Ono et al., 2001) embryos were obtained from crosses between adult zebrafish. The HuC promoter drives green fluorescent protein (GFP) expression in all neurons, and was used here to visualize motor axons in some experiments.

Generation of transient transgenic embryos expressing vesicle-associated membrane protein-GFP. A plasmid encoding upstream activation sequence (UAS)-vesicle-associated membrane protein 2 (VAMP2)-GFP (Jontes et al., 2004) was coinjected with a plasmid encoding $\alpha$-tubulingalactose 4 (GAL4) $(7.5-15 \mathrm{ng} / \mu \mathrm{l})$ in Yamamoto Ringer's (in mm: 17 $\mathrm{NaCl}, 0.4 \mathrm{KCl}, 0.27 \mathrm{CaCl}_{2}, 0.5 \mathrm{MgCl}_{2}, 2.4 \mathrm{NaHCO}_{3}, \mathrm{pH} 7.3$, plus $0.05 \%$ phenol red) into embryos at the one to four cell stage. Thus, GAL4 activation of UAS drove VAMP2-GFP expression in all cells in a mosaic manner. Embryos were then raised to $18-20$ hours postfertilization (hpf) at $28.5^{\circ} \mathrm{C}$ in $\mathrm{E} 3$ medium (in mM: $5 \mathrm{NaCl}, 0.17 \mathrm{KCl}, 0.33 \mathrm{CaCl}_{2}, 0.33$ $\mathrm{MgSO}_{4}$ ) and evaluated for GFP expression in the spinal cord. Embryos in which primary motor neurons were VAMP-GFP + were selected for rhodamine $\alpha$-bungarotoxin ( $\alpha \mathrm{BTX})$ staining and subsequent imaging as described below.

VAMP-GFP expression was observed in many types of neurons, including primary motor neurons caudal primary $(\mathrm{CaP})$, middle primary $(\mathrm{MiP})$, rostral primary $(\mathrm{RoP})$, and variable primary $(\mathrm{VaP})$. Motor neuron identity was determined by the location and size of the neuronal cell body and the territory innervated by the outgrowing motor axon (Myers et al., 1986) and was confirmed by postimaging immunostaining. Diffuse VAMP-GFP within axons and punctate VAMP-GFP clusters were observed in motor neuron axons, growth cones, and fine filopodia during early stages of axon outgrowth and synaptogenesis, as previously reported for VAMP-GFP and other synaptic vesicle proteins during early neural development (Sabo and McAllister, 2003; Jontes et al., 2004). Colocalization of VAMP-GFP with the synaptic vesicle protein SV2 after immunostaining (see below, Whole-mount immunostaining of zebrafish embryos) confirms that VAMP-GFP accurately marks the location of synaptic vesicle clusters in zebrafish (supplemental Fig. $1 \mathrm{~A}$, available at www.jneurosci.org as supplemental material) (Panzer et al., 2005). In addition, VAMP-GFP expression did not affect motor axon outgrowth or synaptogenesis (supplemental Fig. $1 B$, available at www.jneurosci.org as supplemental material).

Fluorescent $\alpha B T X$ staining in live embryos. At $\sim 18-24 \mathrm{hpf}$, wild-type, HuC:GFP, or transient transgenic embryos were briefly anesthetized in 0.02\% Tricaine (Sigma, St. Louis, MO) in Hank's solution (in mM: 137 $\mathrm{NaCl}, 5.4 \mathrm{KCl}, 0.25 \mathrm{~mm} \mathrm{Na}_{2} \mathrm{HPO}_{4}, 0.44 \mathrm{KH}_{2} \mathrm{PO}_{4}, 1.3 \mathrm{CaCl}_{2}, 1.0 \mathrm{MgSO}_{4}$, $4.2 \mathrm{NaHCO}_{3}$ ). The most caudal one to two segments of the tail were removed using a scalpel. Embryos were rinsed in Hank's solution and incubated in rhodamine $\alpha$ BTX ( $15 \mu \mathrm{g} / \mathrm{ml}$; Molecular Probes, Eugene, OR) for $1.5 \mathrm{~h}$ at room temperature followed by extensive washing in Hank's solution. We empirically determined that this $\alpha$ BTX staining protocol resulted in labeling of AChRs that was optically saturating but nonparalytic. Absence of paralysis was determined by normal response of embryos to head or tail tap. Optical saturation of AChRs was defined as failure of Cy $5 \alpha \mathrm{BTX}$, applied immediately after the initial rhodamine $\alpha \mathrm{BTX}$ application, to result in $\mathrm{Cy} 5 \alpha \mathrm{BTX}$ labeling of receptors that could be detected optically, even with the highest gain settings of the confocal photomultiplier tube. Optically saturating but nonparalytic labeling of AChR receptors did not significantly alter motor axon outgrowth or neuromuscular synapse formation. Embryos were then rinsed with Hank's solution before imaging. Using this technique, AChRs inserted into the muscle fiber membrane after $\alpha$ BTX application are unlabeled and therefore not detected during in vivo imaging.

To examine the localization of newly inserted receptors, in one series of experiments, the location of AChRs that were inserted in the muscle fiber membrane at the time of initial rhodamine $\alpha$ BTX labeling (old AChRs) was compared with the location of subsequently inserted AChRs (new AChRs) that were labeled with Cy5 $\alpha$ BTX after a 2, 4, or 7 h delay. Embryos were then processed for immunostaining.

In vivo imaging. Embryos were placed in $1.2 \%$ low melting temperature agarose (SeaPlaque; Cambrex, East Rutherford, NJ) in Hank's solution in a modified imaging chamber (Warner Instruments, Hamden, CT) perfused with Hank's solution at $28.5^{\circ} \mathrm{C}$. In transient transgenic VAMP-GFP embryos, confocal z-stacks of images were obtained approximately every $10-20$ min for $2-8$ h (TCS 4 D or SP2 system; Leica, Nussloch, Germany). In HuC:GFP embryos, confocal z-stacks were obtained every $1 \mathrm{~h}$ for $6 \mathrm{~h}$. Unless otherwise stated, each movie panel is a single plane projection of a Z-stack of $20-601-\mu \mathrm{m}$-thick planes taken at the indicated time interval. Z-stacks of up to $60 \mu \mathrm{m}$ were necessary in some embryos, because the initial path of outgrowing motor axons is not flat and because, in older embryos, motor axon arbors become elaborate in three dimensions (Fig. 1) (Panzer et al., 2005). Spontaneous movements and blood cell circulation, indicators of embryo viability, were observed throughout the duration of movies that were subsequently analyzed. At the conclusion of the imaging session, embryos were re-anesthetized, fixed, and processed for immunostaining.

In transient transgenic embryos expressing VAMP-GFP at $\sim 24 \mathrm{hpf}$, relatively few motor axon branches or neuromuscular synapses are present, whereas by $72 \mathrm{hpf}$ axons have branched into their appropriate, cell-specific territory, and many neuromuscular synapses are present (supplemental Fig. 1C, available at www.jneurosci.org as supplemental material). In vivo imaging of VAMP-GFP + primary motor neurons showed that motor axons were extended at a rate of $10.1 \pm 0.8 \mu \mathrm{m} / \mathrm{h}$ (mean \pm SEM; $n=1022-30$ hpf embryos, 10 neurons), similar to that observed in previous in vivo analyses using single cell fills (Eisen et al., 1986; Myers et al., 1986; Westerfield et al., 1986). Thus, the imaging procedures used in the present study do not interfere with axon outgrowth or neuromuscular synaptogenesis.

AChR blockade. Rhodamine $\alpha \mathrm{BTX}$ was diluted to $0.25 \mathrm{~mm}$ in Yamamoto Ringer's with $0.05 \%$ phenol red and injected directly into the yolk of 12-14 hpf embryos (Lefebvre et al., 2004). This approach was used to achieve sustained paralysis, because it likely achieves a higher concentration of $\alpha \mathrm{BTX}$ within embryonic muscle than bath application does, both by bypassing the skin, a natural barrier to toxins, and by providing sustained exposure to $\alpha \mathrm{BTX}$ released by the yolk sac over many hours. At $24 \mathrm{hpf}$, embryos were scored for motility by evaluating responses to head and tail tap, and only those embryos that were completely paralyzed were collected, fixed, and immunostained.

Sodium channel blockade. Embryos were raised from 10 to $21 \mathrm{hpf}$ in $0.01 \%$ tricaine in E3. At $21 \mathrm{hpf}$, embryos were scored for motility by evaluating spontaneous tail movements, and only those embryos that were completely immotile were collected, fixed, and immunostained.

Whole-mount immunostaining of zebrafish embryos. Embryos were anesthetized, fixed, and immunostained as described previously (Panzer et al., 2005) using antibodies against SV2 (Developmental Studies Hybridoma Bank, Iowa City, IA) and/or GFP (Chemicon, Temecula, CA) and a fluorescently conjugated secondary antibody (Jackson ImmunoResearch, West Grove, PA). Immunostained embryos were examined using confocal microscopy. Unless otherwise stated, each figure panel showing immunostaining is a single-plane projection of a $z$-stack of $20-601-\mu$ m-thick planes. 
Analyses of prepatterned AChR clusters, presynaptic vesicle clusters, and synapse formation. AChR or presynaptic vesicle cluster number and area were measured from single-plane projections of confocal image stacks using interactive software (MetaMorph; Molecular Dynamics, Sunnyvale, CA). The number and intensity of pixels in a line parallel to the longest axis of a cluster were measured to analyze changes in AChR cluster length and intensity over time. Presynaptic and postsynaptic clusters were scored as synapses if there was at least $30 \%$ pixel overlap between presynaptic and postsynaptic labeling.

To quantify the contribution of prepatterned AChR clusters to synapses, each cluster present in the first frame of a time-lapse movie was analyzed and placed into one of three categories: present but subsequently disappeared; present with a VAMP-GFP + cluster overlying at least $30 \%$ of the AChR cluster, and thus innervated (synaptic); and present throughout the movie but not innervated during the imaging interval (nonsynaptic). Preliminary analyses suggested that the $30 \%$ colocalization criteria is the minimum for reliable identification of a synapse at the early embryonic ages examined here (see also Panzer et al., 2005). Synapses were confirmed after subsequent immunostaining of presynaptic vesicles with antibodies against SV2. The percentage of events in which an AChR cluster was present in advance of a presynaptic vesicle cluster and in which a presynaptic vesicle cluster was present followed by appearance of an AChR cluster was also determined.

Quantification of growth cone and filopodia dynamics. To quantify axon and growth cone outgrowth with respect to prepatterned AChR clusters, the position of a growth cone was determined from a point in its geometric center. The closest AChR cluster in advance of the growth cone was defined as a potential target AChR cluster. Three angles were then measured: angle 1, the angle between the actual growth cone trajectory and the AChR cluster; angle 2 , the angle between the actual trajectory and the initial trajectory if the growth cone were to grow in a straight line; and angle 3, the angle between the initial trajectory and the target AChR cluster (see Fig. 3D). The distribution of angles 1 and 2 was evaluated, and the relationship between angle 2 and angle 3 was analyzed by linear regression. In some cases, more than one time interval of axon outgrowth was analyzed per neuron, and this number is reported as an outgrowth event.

To quantify the direction of filopodial extension with respect to prepatterned AChR clusters, only filopodia extended near AChR clusters that were not along the direct path of axon extension were analyzed. This is because we wanted to avoid a bias in the quantification that would have arisen if filopodia tended to grow out in the direction of axon extension, and AChR clusters happened to be along this pathway. All filopodia within a $5 \mu \mathrm{m}$ radius of an axon or growth cone region nearest the target AChR cluster were analyzed. The mean distance from an axon or growth cone to a target AChR cluster was $15 \mu \mathrm{m}$. The presence of multiple AChR clusters that were an equal distance from an axon or filopodia was rare, and these cases were not analyzed.

The length of the filopodia, the actual trajectory of the filopodia, and the straightest, shortest trajectory between the base of the filopodia at the axon and an AChR cluster were determined in each movie frame (see Fig. $4 D$ ). The length of the filopodia and the angle between its actual trajectory and the straightest trajectory with respect to an AChR cluster were plotted using polar coordinates where each line segment represents filopodia length. Similarly, the length of filopodia, and the angles between the filopodia and a control region, defined as an area $15 \mu \mathrm{m}$ from an axon or growth cone with no AChR clusters in the vicinity were also measured and plotted. The cumulative percentage of filopodia extended at various angles with respect to an $\mathrm{AChR}$ cluster or control region was plotted and differences were assessed (Kolmogorov-Smirnov test).

\section{Results}

\section{Prepatterned AChR clusters are dynamic}

Each of the three primary motor neurons per spinal cord hemisegment ( $\mathrm{CaP}, \mathrm{MiP}$, and $\mathrm{RoP}$ ) sends an axon out of the spinal cord between 16 and 24 hpf. Primary motor axons then grow ventrally along the lateral surface of the notochord to the socalled choice point at the horizontal myosepta (midline) of the somite. Axons pause at the choice point for several hours, then grow out across the medial surface $(\mathrm{CaP}, \mathrm{MiP})$, or branch near the midline (RoP, VaP) of the myotome, and subsequently all axons branch extensively (Eisen et al., 1986). Neuromuscular synapses are formed en passant along the axon shaft and branches (Eisen et al., 1986; Myers et al., 1986; Westerfield et al., 1986; Panzer et al., 2005). Approximately $5 \mathrm{~h}$ after initiation of primary motor axon outgrowth, the axons of secondary motor axons 
( $\sim 20-30$ per hemisegment) begin to extend into the periphery along the pathways pioneered by primary motor axons and also form en passant synapses (Myers et al., 1986; Westerfield et al., 1986).

In fixed and immunostained embryos at $24 \mathrm{hpf}$, AChR clusters are present on each muscle fiber along the medial surface of the myotome (Fig. $1 A$, caudalmost segments; $D$ ), on many muscle fibers in lateral muscle layers, and along the lateral myosepta, well in advance of motor axon outgrowth from the spinal cord (Panzer et al., 2005). These AChR clusters are thus prepatterned on muscle fibers in advance of innervation (Yang et al., 2000; Lin et al., 2001; Yang et al., 2001). Prepatterned AChR clusters are elongated and diffuse in caudal and thus younger myotomes, but are small, punctate, and reduced in number in more rostral, older myotomes (Fig. 1A-D). The largest prepatterned AChR clusters are present at the choice point; these clusters persist as motor axons enter the myotome and the first neuromuscular synapses are made at these prepatterned AChR clusters (Fig. $1 \mathrm{~B}$, bracket) (Panzer et al., 2005). These observations suggest that initially diffuse, elongated prepatterned AChR clusters coalesce, and some AChR clusters disappear, as innervation occurs.

To directly determine the fate of prepatterned AChR clusters as motor axons grow into the myotome, AChRs were labeled with a nonparalyzing dose of rhodamine $\alpha \mathrm{BTX}$ in HuC:GFP embryos, in which all neurons including primary motor neurons and axons express GFP, and confocal z-stacks were obtained over time $(n=$ 4 20-26 hpf embryos, 19 myotome segments). At the beginning of imaging, motor axons had not exited the spinal cord (Fig. $2 \mathrm{~A}$, panel 0:00). Prepatterned AChR clusters are initially elongated and diffuse, and over several hours, most if not all clusters coalesce (Fig. $2 \mathrm{~A}$, compare panels 1:00, 3:00). During a $6 \mathrm{~h}$ interval, AChR cluster width is reduced (Fig. $2 F$ ) and fluorescence intensity increases (Fig. $2 G$ ), consistent with the coalescing of each cluster. During this interval, $20 \%$ of all prepatterned AChR clusters disappear, as demonstrated both by comparing subsequent images qualitatively (Fig. $2 B$, arrow) as well as quantifying changes in individual cluster length and intensity (Fig. 2C, $F-H$ ). This dynamic redistribution of AChRs usually begins in advance of motor axon outgrowth into the myotome. Thirty percent of all prepatterned AChR clusters persist and become innervated during a $6 \mathrm{~h}$ interval (Fig. 2D, arrow), as demonstrated by the presence of GFP + axons apposed to AChR clusters (Fig. $2 D$, panel 5:00, asterisk) as well as by postimaging immunostaining for presynaptic vesicles (Fig. 2D, last panel). As stated above, $20 \%$ of prepatterned AChR clusters that are not innervated disappear. However, about one-half of the prepatterned AChR clusters are neither dispersed nor innervated during a $6 \mathrm{~h}$ imaging interval. Given the absence of uninnervated AChR clusters in older embryos (Panzer et al., 2005), these clusters must either be innervated or disappear over longer intervals. These observations show that prepatterned AChR clusters are highly dynamic before and during motor axon outgrowth into the myotome, and that some of these clusters are incorporated into synapses, whereas others are dispersed or persist in an uninnervated state.

\section{Motor axon outgrowth occurs along prepatterned AChR clusters}

In vivo imaging of VAMP-GFP + primary motor axon outgrowth in transiently transgenic embryos was used to examine the spatial and temporal dynamics of these events with respect to prepatterned AChR clusters over time $(n=2020-30$ hpf embryos, 29 growth cones, 44 outgrowth events). In vivo imaging showed that, at any given time, AChR clusters are observed in advance, or within two to three muscle fibers, of $\sim 75 \%$ (33 of 44 ) of outgrowing motor axons (Figs. 1C, $3 A, 4 A, 6 A, E$ ). Motor axon growth cones grow directly toward, and then along, and eventually innervate, prepatterned AChR clusters (Fig. 3B). Continual growth toward, and innervation of, prepatterned $\mathrm{AChR}$ clusters result in motor axon extension across the medial surface of the myotome (Fig. 3B). Thus, motor axons appear to follow a pathway across the medial surface of the myotome that is spatially coincident with prepatterned AChR clusters. These results contrast with previous reports that $\mathrm{AChR}$ clustering and motor axon outgrowth are simultaneous in zebrafish (Liu and Westerfield, 1992) and raise the possibility that, in at least some cases, prepatterned AChR clusters themselves, or cues that are copatterned with such clusters, might direct motor axon outgrowth.

These possibilities are further supported by the observation that the location of prepatterned AChR clusters predicts growth cone turning. For example, in Figure $3 B$, prepatterned, previously uncontacted, AChR clusters are located $\sim 15 \mu \mathrm{m}$ rostral (and somewhat lateral) to the motor axon growth cone in panel $2: 20$, and in the subsequent $2 \mathrm{~h}$, the growth cone turns $65^{\circ}$ toward and contacts these AChR clusters. Sixty-three percent of growth cones are extended with an angle $\leq 10^{\circ}$, and $95 \%$ are extended at an angle of $\leq 30^{\circ}$, with respect to a prepatterned, previously uncontacted, AChR cluster (Fig. 3E, black bars). Growth cones were observed to turn toward a prepatterned AChR cluster over a wide range of angles, from 10 to $130^{\circ}$ (Fig. $3 E$, gray bars). For the population of growth cones that were observed over time, a significant correlation exists between the location of a prepatterned AChR cluster with respect to the initial trajectory of the motor axon, and the angle that the growth cone eventually turns toward that cluster (Fig. $3 F$ ). These observations show that the direction of motor axon outgrowth is dynamically altered so that axons continually extend along a pathway that is spatially coincident with prepatterned AChR clusters that they will eventually contact.

\section{Motor axon filopodia are preferentially extended toward prepatterned AChR clusters}

In the course of time-lapse imaging of motor axon outgrowth to, and interactions with, prepatterned AChR clusters, many examples were observed of filopodia that were rapidly extended toward and touched prepatterned AChR clusters (Fig. 4A-C). In some cases, filopodia were extended toward a prepatterned AChR cluster (Fig. $4 B$, arrow), touched it (Fig. $4 B$, panels 0:10 and 3:30, asterisk), and retracted. In other cases, filopodia were observed that contacted a prepatterned AChR cluster (Fig. 4C, arrowhead), dilated (Fig. 4C, panel 4:20), and subsequently persisted as an axon branch for the duration of the imaging interval (Fig. 4C, panel 5:10).

Quantitative analyses showed that filopodia were preferentially extended toward prepatterned AChR clusters. When the direction of all of the filopodia extended from a single motor axon was plotted using polar coordinates, the majority were extended $\leq 30^{\circ}$ with respect to a target prepatterned AChR cluster (Fig. $4 E$ ). In contrast, when the direction of filopodial extension was analyzed with respect to a control region without an AChR cluster in the vicinity, extension was random (Fig. $4 F$ ). For all filopodia from all motor neurons imaged over time, $\sim 30 \%$ of filopodia were extended at an angle $\leq 10^{\circ}$ with respect to a prepatterned AChR cluster located a mean of $15 \mu \mathrm{m}$ away, and $54 \%$ of filopodia were extended at an angle $\leq 30^{\circ}$ of such clusters (Fig. $4 G$, gray line). In contrast, when no AChR cluster was present, filopodia extension was nondirectional (Fig. 4G, black line). 

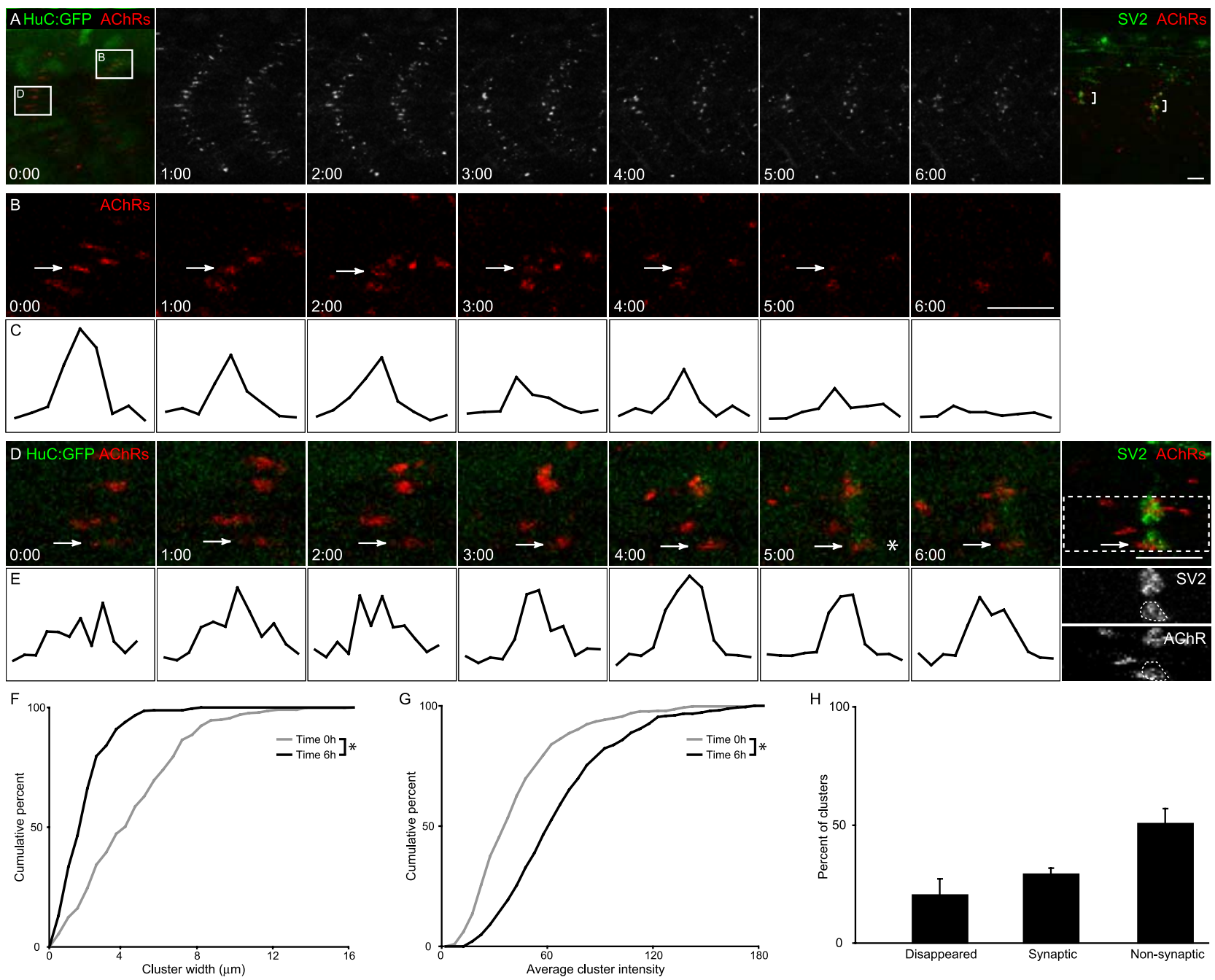

Figure 2. Dynamics of prepatterned AChR clusters. Rhodamine $\alpha$ BTX-labeled AChRs (red) imaged in transgenic embryo expressing GFP in neurons to visualize motor axons (HuC:GFP; green) from $20-26 \mathrm{hpf}$ at $1 \mathrm{~h}$ intervals (supplemental movie 1 , available at www.jneurosci.org as supplemental material). $\boldsymbol{A}$, Time-lapse images of prepatterned AChR clusters. The first movie plane was taken at time 0:00, before motor axon outgrowth from the spinal cord. Boxed regions in the first panel are shown at higher magnification in $\boldsymbol{B}$ and $\boldsymbol{D}$. Prepatterned $A C h R$ clusters are initially elongated and diffuse and coalesce over time (e.g., compare panels 1:00 and 3:00). The final panel is postimaging immunostaining for presynaptic vesicles (SV2; green) that demonstrates that motor axons have grown to and synapses have been established at the choice point (bracket) by 6:00. Scale bar, $10 \mu \mathrm{m}$. $\boldsymbol{B}$, Higher magnification of boxed region in $\boldsymbol{A}$. As motor axons exit the spinal cord and innervate the choice point, many prepatterned AChR clusters disappear (disappearing cluster indicated by arrow). In this small region, many prepatterned AChRs disappear over the $6 \mathrm{~h}$ imaging interval (compare cluster marked with an arrow from panels 0:00 to 6:00). However, throughout the myotome, 20\% of prepatterned AChR clusters disappear over a $6 \mathrm{~h} \mathrm{imaging} \mathrm{interval.} \mathrm{Scale} \mathrm{bar,} 10 \mu \mathrm{m}$. C, Line scan ( $8 \mu \mathrm{m}$ in length) through the cluster marked with an arrow in $\boldsymbol{B}$ shows that cluster fluorescence intensity (arbitrary units) and length decrease gradually over the $6 \mathrm{~h}$ imaging interval. $D$, Higher magnification of boxed region in $A$. In this small region, two of the four prepatterned AChR clusters present at the first views are incorporated into synapses (compare cluster marked with an arrow in panels 0:00-6:00) as evidenced by the appearance of a GFP + axon over the AChR cluster at panel 5:00 (asterisk) that persists to 6:00. However, throughout the myotome, 30\% of prepatterned AChR clusters are incorporated into synapses. $\boldsymbol{D}^{\prime}$, Postimaging immunostaining demonstrating an SV2 + vesicle cluster formed at this AChR cluster. $\mathbf{D}^{\prime \prime}, \boldsymbol{D}^{\prime \prime \prime}$, Single-channel images of the boxed region in $\boldsymbol{D}^{\prime}$, demonstrating colocalization of the SV2 + vesicle cluster (indicated by dashed line) with the AChR cluster. Scale bar, $10 \mu \mathrm{m}$. $\boldsymbol{E}$, Line scan (11 $\mu \mathrm{m}$ ) through the AChR cluster marked with an arrow in $\boldsymbol{D}$ shows that cluster width gradually decreases and that fluorescence persists throughout the $6 \mathrm{~h}$ imaging interval. $\boldsymbol{F}$, Quantification of $A C h R$ cluster length at 0:00 and 6:00, demonstrating that prepatterned AChR clusters coalesce and become significantly reduced in length over time ( $n=4$ fish, 19 myotome segments; Kolmogorov-Smirnov test, $p<0.001)$. $\boldsymbol{G}$, Quantification of $A C h R$ cluster intensity at 0:00 and 6:00, determined by measuring the average pixel intensity along a line scan, demonstrating that prepatterned $A C h R$ clusters significantly increase in fluorescence over time ( $n=4$ fish, 19 myotome segments; Kolmogorov-Smirnov test, $p<0.001$ ). $\boldsymbol{H}$, Quantification of the fate of prepatterned AChR clusters. Of all prepatterned AChR clusters, $20 \%$ disappeared, $30 \%$ become synaptic during the $6 \mathrm{~h}$ imaging interval, and 50\% remain nonsynaptic during the imaging interval ( $n=4$ fish, 14 myotome segments). Error bars indicate SE.

These results show that motor axon filopodia are preferentially extended toward prepatterned AChR clusters.

Time-lapse imaging demonstrated that filopodia are not extended with equal frequency from all areas of the motor axon. The majority of filopodia ( $90 \%)$ were extended from axon locations that contained VAMP-GFP+ clusters of synaptic vesicles. Seventy percent of the VAMP-GFP + clusters from which filopodia extended were also apposed to AChR clusters (63\% of all filopodia) and were thus synaptic sites (Fig. $5 A-A^{\prime \prime}, D$ ). Only $10 \%$ of filopodia were extended from locations on the axon shaft that lacked VAMP-GFP + clusters (Fig. $5 C-C^{\prime \prime}, D$ ). These results show that filopodia are preferentially extended from synaptic sites on axons, consistent with observations of axon branch formation in Xenopus laevis tadpoles (Javaherian and Cline, 2005).

Prepatterned AChR clusters determine the location of initial neuromuscular synapses

The results described above show that prepatterned AChR clusters play an important role in determining the direction of motor axon outgrowth. We next asked whether initial neuromuscular 

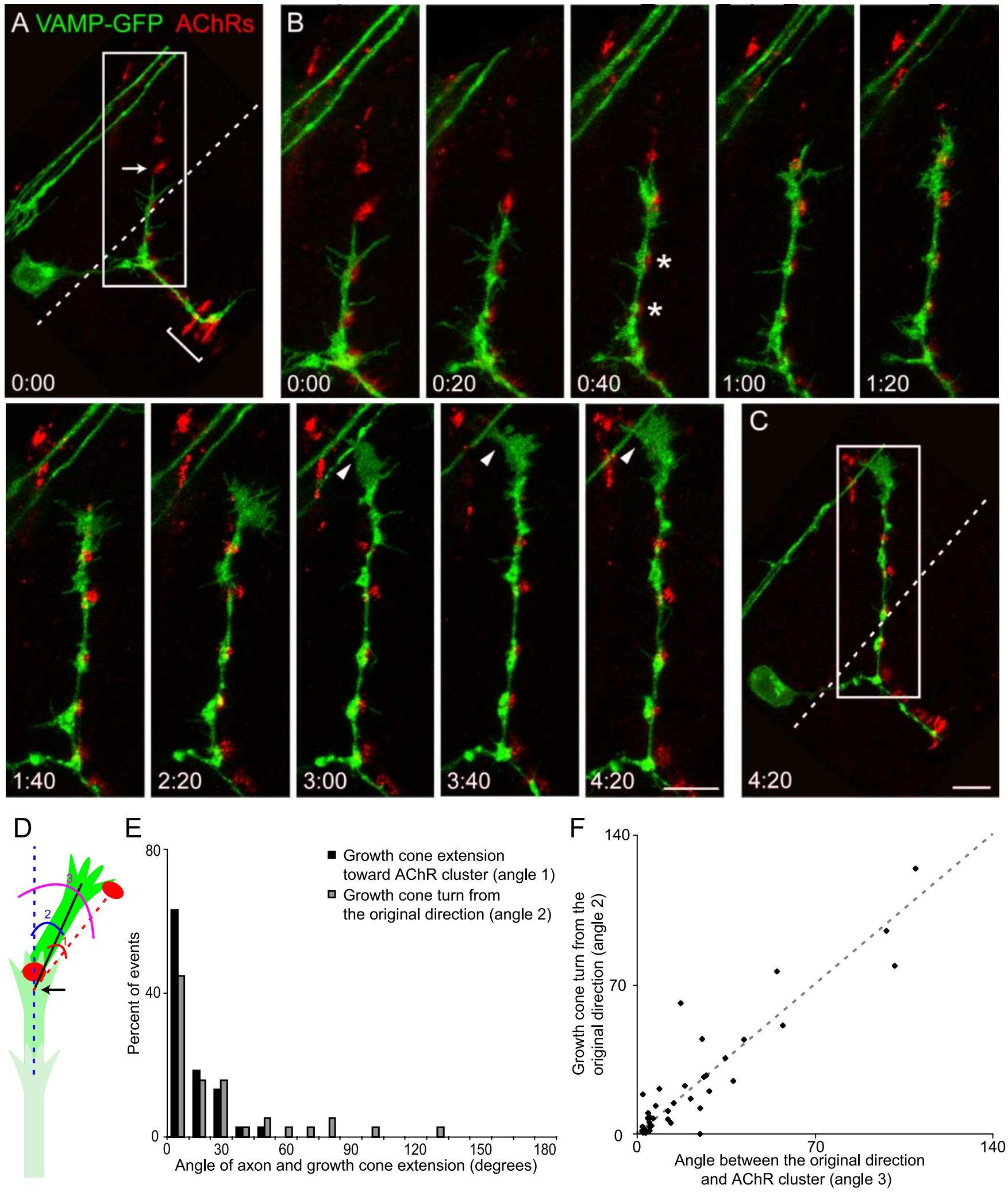

Figure 3. Motor axon growth cones preferentially extend toward prepatterned AChR clusters. A-C, A primary motor neuron, MiP, expressing VAMP-GFP (green) and AChR clusters labeled with rhodamine $\alpha$ BTX (red) from a $\sim 24 \mathrm{hpf}$ embryo were imaged for $>4 \mathrm{~h}$ at intervals of $20 \mathrm{~min}$ (supplemental movie 2, available at www.jneurosci.org as supplemental material). The dashed line indicates the edge of the spinal cord. In this series of images, the position of AChRs is fixed while a single motor axon growth cone advances across the field of view. In the supplemental movie (available at www.jneurosci.org as supplemental material), AChR clusters near the bottom of the frame appear to move because the embryo is growing. Because we did not attempt to focus on this region during image capture, these clusters come in and out of the field of view on several occasions. $A$, At the start of time-lapse imaging, MiP has extended to the choice point (bracket), and a dorsal axon branch is growing toward prepatterned AChR clusters (arrow). The boxed region is shown at higher magnification in $\boldsymbol{B}$. $\boldsymbol{B}$, Time-lapse images of the MiP growth cone extending toward, contacting, and then extending beyond, prepatterned AChR clusters. In some cases, VAMP-GFP + clusters of presynaptic vesicles accumulate over prepatterned AChR clusters (panel 0:40, asterisks). In panels 3:00 - 4:20, the growth cone turns $65^{\circ}$ toward prepatterned AChR clusters at the dorsal edge of the myotome and lateral myosepta (arrowhead). Scale bar, $10 \mu \mathrm{m}$. C, At the end of time-lapse imaging, the MiP axon has reached the dorsal edge of the myotome and has just contacted AChR clusters located at the dorsal edge of the myosepta. The boxed (Figure legend continues.) 
synapses are established at prepatterned AChR clusters $(n=19$ 20-30 hpf embryos, 34 motor neurons, 75 synapse formation events).

In $81 \%$ of synapse formation events, a motor axon growth cone or filopodia was observed to reach a prepatterned AChR cluster and subsequently extend beyond it. In these cases, a VAMP-GFP + cluster, at least $2 \mu \mathrm{m}$ in length, was subsequently formed over the AChR cluster (Fig. 6A,E). The formation of VAMP-GFP + clusters occurred rapidly, within 20 min to $1.5 \mathrm{~h}$ after contact (Fig. $6 B$, panel 1:00; $F$, panel 4:00, asterisk) and persisted for several hours, or until the end of the imaging session (Fig. 6B, panel 1:40; F, panel 4:40). These results show that, in $\sim 80 \%$ of cases, clustering of presynaptic material, a requisite step in neuromuscular synapse formation, occurs at prepatterned AChR clusters.

In $11 \%$ of synapse formation events, a motor axon growth cone or filopodia was observed that had extended over one or more AChR clusters at the beginning of the imaging session. In these cases, we were unable to establish whether AChR clusters were indeed prepatterned (i.e., present before motor axon contact). However, in these cases, VAMP-GFP+ clusters subsequently appeared over AChR clusters (Fig. 3B, panel 0:40, asterisks). Together with the results above, theses results indicate that, in $\sim 90 \%$ of cases, AChR clusters are present before clustering of VAMP.

Before $\sim 24 \mathrm{hpf}$, in only $5 \%$ of events did motor axons appear to initiate neuromuscular synaptogenesis. In these cases, a motor axon or growth cone was present first, followed by the appearance of an AChR cluster (Fig. 6F, G, arrowhead), and subsequently, a VAMP-GFP+ cluster appeared at this site (Fig. 6F, panel 4:40, empty arrowhead). In 2 of 75 events (3\%), VAMPGFP + and AChR clusters appeared simultaneously (data not shown). Of 75 synapses formation events, VAMP-GFP + clusters were never observed to form before AChR clustering. Together with synapse formation at prepatterned AChR clusters, these results show that, in the vast majority of cases of initial synaptogenesis in muscle, postsynaptic AChR clusters are formed before presynaptic clusters of synaptic vesicles accumulate.

\section{Redistribution of AChRs from prepatterned clusters and preferential insertion of new receptors at synaptic sites}

To determine the location of newly inserted AChRs during initial stages of synaptogenesis, all AChRs were optically saturated with rhodamine $\alpha \mathrm{BTX}$ at $20 \mathrm{hpf}$, and 2, 4, or $7 \mathrm{~h}$ later, newly inserted AChRs were labeled with Cy5 $\alpha$ BTX. The location of existing (old) AChRs and receptors inserted since the initial rhodamine $\alpha$ BTX labeling (new) was compared with the location of motor axons and terminals visualized after immunostaining.

After a 2-4 h interval after initial labeling of old AChRs, all prepatterned AChRs coalesced and some disappeared, consistent with immunostaining and in vivo imaging observations (Fig. 7, compare $\left.A^{\prime}, B^{\prime}\right)$. Moreover, the majority of AChR clusters beneath SV2 + terminals, and thus at synapses, were composed of both old and new AChRs (Fig. $7 A-B^{\prime \prime}$ ), whereas the majority of nonsynaptic sites (Fig. $7 B$, arrows) were composed only of old AChRs (Fig. 7D). Few if any AChR clusters are observed that contain only newly inserted AChRs (Fig. $\left.7 B^{\prime \prime}, D\right)$. This result suggests that new AChRs are preferentially inserted at synapses and not at sites of nonsynaptic AChR clusters.

Strikingly, after a $7 \mathrm{~h}$ interval, old AChRs labeled at $20 \mathrm{hpf}$ were observed to be located in clusters beneath presynaptic nerve terminals throughout the myotome (Fig. 7, compare $A, A^{\prime}, B, B^{\prime}$ with $\left.C, C^{\prime}\right)$. This observation suggests that, although some prepatterned $\mathrm{AChR}$ clusters disappear, receptors in those clusters may be reclustered at synapses (Fig. $7 C, C^{\prime}$ ). We cannot rule out the possibility that some old AChRs contained within synaptic clusters at $27 \mathrm{hpf}$ may have been originally diffusely distributed in the muscle membrane at $20 \mathrm{hpf}$ and not present in prepatterned clusters per se. Moreover, in vivo imaging observations showed that nonsynaptic AChR clusters, containing old AChRs labeled several hours earlier, occasionally appeared on muscle fibers $10-20 \mu \mathrm{m}$ in advance of or beneath motor axons or growth cones (data not shown) (Fig. 6F,G). Thus, some nonsynaptic AChR clusters are primarily formed via redistribution of AChRs that were in the membrane at an earlier time. These data show that AChRs that are present in the muscle fiber membrane before motor axon outgrowth into the myotome are redistributed, such that all synapses formed by $27 \mathrm{hpf}$ contain at least some of this original population of receptors.

\section{AChR activity or AChR clusters are not required for initial neuromuscular synaptogenesis}

In mouse, both presynaptic release of $\mathrm{ACh}$ and the depolarization of muscle fibers have been proposed as signals that lead to the dispersion of prepatterned AChR clusters and their redistribution beneath nascent motor nerve terminals (Lin et al., 2001, 2005; Yang et al., 2001; Misgeld et al., 2002). Moreover, given that growth cones and filopodia are preferentially extended toward prepatterned AChR clusters, we wondered whether AChRs might detect presynaptic ACh release, leading to signaling that culminated in synapse formation. These possibilities were tested by examining prepatterned AChR clusters, motor axon outgrowth, and neuromuscular synapse formation in wild-type zebrafish in which AChRs were blocked with $\alpha$ BTX from 12 to $24 \mathrm{hpf}$.

In caudal and thus younger segments of paralyzed embryos at $24 \mathrm{hpf}$, the number and total area of prepatterned AChR clusters, and the dispersion of some prepatterned AChR clusters, were similar to control embryos (Fig. $8 A^{\prime \prime}, B^{\prime \prime}, G$ ). Thus AChR activity is not required for the formation or dispersion of prepatterned AChR clusters.

In both rostral (Fig. $8 A, B$ ) and middle (Fig. $8 A^{\prime}, B^{\prime}$ ) segments, the outgrowth of primary motor neurons is similar in paralyzed and control embryos (Fig. 8D). Moreover, the number and total area of SV2+ presynaptic vesicle clusters, postsynaptic AChR clusters, and synapses are similar (Fig. 8E), although the distribution of areas of individual SV2 + clusters was shifted to larger

$\leftarrow$

(Figure legend continued.) region is the same as in A. Scale bar, $10 \mu \mathrm{m}$. D, To quantify axon and growth cone outgrowth with respect to prepatterned AChR clusters, the position of a growth cone was determined from a point in its geometric center (arrow). The closest AChR cluster in advance of the growth cone was defined as a potential target AChR cluster (red oval). Three angles were then measured: angle 1, the angle between the actual growth cone trajectory (black line) and a straight trajectory toward the AChR cluster (red dashed line); angle 2, the angle between the actual trajectory and the initial trajectory if the growth cone were to grow in a straight line (blue dashed line); and angle 3 , the angle between the initial trajectory and the target $A C h R$ cluster ( $n=922-30$ hpf embryos, 9 motor neurons, 38 growth cone outgrowth events). $\boldsymbol{E}$, The distribution of angles 1 and 2 . Sixty-three percent of growth cones are extended with an angle $\leq 10^{\circ}$, and $95 \%$ are extended at an angle of $\leq 30^{\circ}$, with respect to a prepatterned AChR cluster (black bars). Growth cones were observed to turn toward a prepatterned $A C h R$ cluster over a wide range of angles, from 10 to $130^{\circ}$ (gray bars). $\boldsymbol{F}$, Angle 2 was plotted against angle 3, and their relationship was analyzed by linear regression. A significant correlation exists between the location of a prepatterned AChR cluster with respect to the initial trajectory of the motor axon (angle 3) and the angle (angle 2) that the growth cone eventually turns toward that cluster ( $r=0.91$ ). 

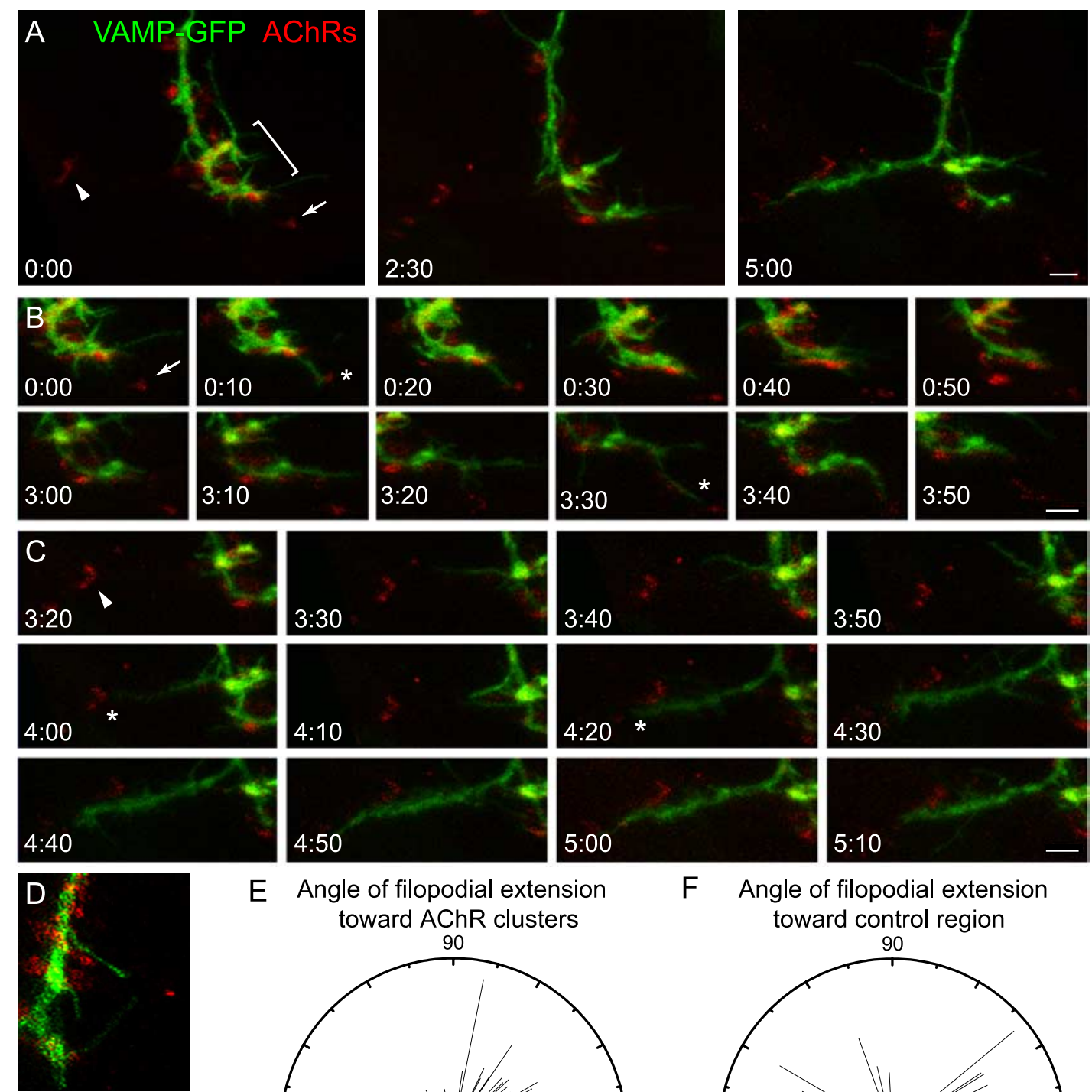

E Angle of filopodial extension

F Angle of filopodial extension toward AChR clusters

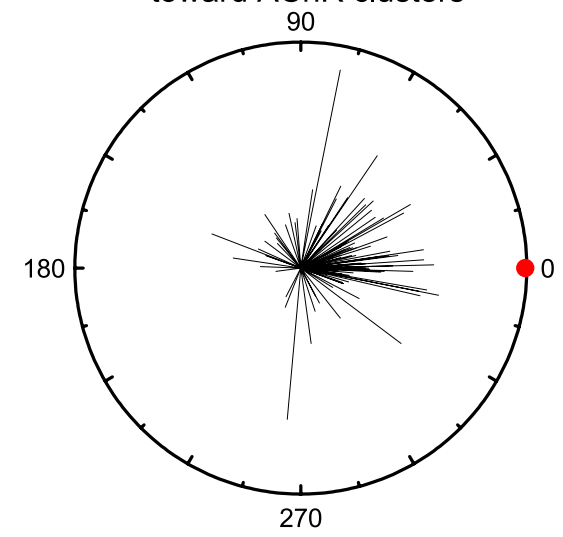
toward control region

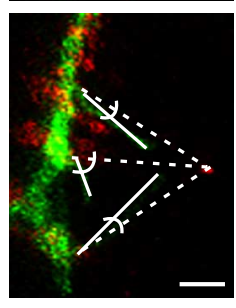

G $\quad 100$

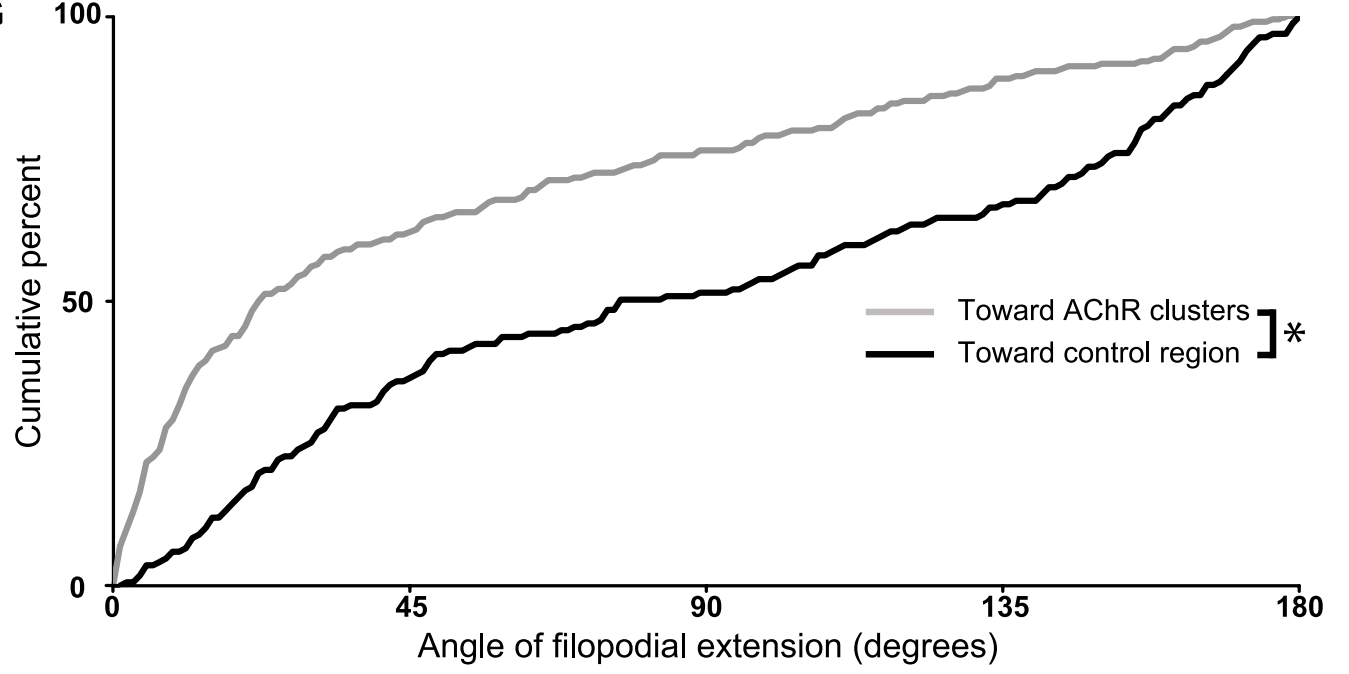


values in paralyzed compared with control embryos (Fig. $8 F$ ), probably reflecting enlargement of the three to four choice point synapses in some myotomes.

In addition to using $\alpha$ BTX to block signaling through AChRs, we also blocked activity with the sodium channel blocker tricaine and found that prepatterned AChR cluster dispersal and motor axon outgrowth were similarly unaffected (supplemental Fig. 2, available at www. jneurosci.org as supplemental material). Blockade of sodium channels with tetrodotoxin (TTX) provided similar results (data not shown). Consistent with previous work in zebrafish, chicken, and rodents, these results show that neither AChR activity nor neuronal activity is required for motor axon outgrowth or initial neuromuscular synapse formation.

Although only those embryos that were completely paralyzed after $\alpha$ BTX application were selected for analysis in the above experiments, it remains possible that this technique might not completely abolish signaling through AChRs. Thus, we next examined neuromuscular synaptogenesis in sofa potato (sop) mutants, in which AChRs are absent as a result of a mutation in the AChR $\delta$ subunit (Ono et al., 2001). As reported previously, no AChR clusters were observed in sop mutant embryos (Fig. 8C$C^{\prime \prime}$ ) (Ono et al., 2001). Moreover, at $24 \mathrm{hpf}$, the extent of primary motor axon outgrowth is similar between sop mutants and normal siblings (Fig. 8D). However, in many segments, the first formed presynaptic SV2 + vesicle clusters, at the choice point, are enlarged in sop mutant embryos compared with normal siblings (Fig. $8 A, C$, brackets). Although the number and total area of SV2 + vesicle clusters are similar (Fig. $8 E$ ), the distribution of individual SV2+ cluster area was shifted to larger values in $s o p$ mutant compared with normal siblings (Fig. $8 F$ ), probably reflecting the enlargement of the three to four presynaptic terminals at the choice point in each myotome. Together with the results of $\alpha$ BTX blockade, these experiments suggest that, perhaps via a negative-feedback loop, AChR signaling limits the size of presynaptic vesicle clusters. However, it is clear from these experiments that AChR activity, and indeed AChRs themselves, are dispensable for motor axon outgrowth. Thus, it may be that cues colocalized with prepatterned AChR clusters, but not the receptors themselves, determine motor axon outgrowth, branching, and initial neuromuscular synaptogenesis.

\section{Discussion}

The observations we report here provide fundamentally new insights into the initial steps of synapse formation. We show that AChR clusters are prepatterned in myotomal muscle before motor axon outgrowth from the spinal cord, and that prepatterned AChR clusters are localized to the pathway of motor axon outgrowth along the myotome. Moreover, motor axon growth cones and filopodia are preferentially extended toward and contact prepatterned AChR clusters. After contact, presynaptic vesicles cluster at these sites, resulting in the formation of neuromuscular synapses. AChR blockade and examination of sop AChR mutants showed that neither receptor activity nor receptor protein is required for these events to occur. Thus, cues that are colocalized with prepatterned AChR clusters, but not the clusters themselves, must regulate motor axon outgrowth, branching, and initial neuromuscular synaptogenesis.

Complementary work in zebrafish to that reported here was published recently by Flanagan-Steet et al. (2005). Flanagan-Steet et al. used time-lapse imaging to show that prepatterned AChR clusters on adaxial slow muscle fibers are incorporated into neuromuscular synapses as axons advance. In a transgenic line in which motor axon outgrowth occasionally did not occur normally, axons were observed to be required for the subsequent stabilization of prepatterned AChR clusters. Together, these studies show that postsynaptic differentiation precedes presynaptic differentiation and that the formation of initial postsynaptic specializations does not require motor axons (see also Panzer et al., 2005). Conversely, initial motor axon outgrowth and cluster-

$\leftarrow$

Figure 4. Motor axon filopodia preferentially extend toward and contact prepatterned AChR clusters. A-C, A primary motor neuron, RoP, expressing VAMP-GFP (green) and prepatterned AChR clusters labeled with rhodamine $\alpha$ BTX (red) from a $\sim 24 \mathrm{hpf}$ embryo imaged for $>5 \mathrm{~h}$ at intervals of $10 \mathrm{~min}$ (supplemental movie 3, available at www.jneurosci.org as supplemental material). Because of focal plane drift, the leftmost AChR cluster in supplemental movie 3 (available at www.jneurosci.org as supplemental material) briefly disappears for the first five frames at the beginning of the movie. $A$, The growth cone pauses at the choice point (bracket) and forms a rostrally extending branch (panel 5:00). Two areas containing prepatterned AChRs are present (panel 0:00: rostral area, arrowhead; caudal and ventral area, arrow). Scale bar, $5 \mu \mathrm{m}$. B, Many filopodia are extended toward the caudal area containing prepatterned AChR clusters (panel 0:00, arrow). Filopodia contact this AChR cluster twice (panels 0:10 and 3:30, asterisk) and retract. Scale bar, $5 \mu \mathrm{m}$. C, Filopodia are also extended toward the rostral area containing prepatterned AChR clusters (panel 3:20, arrowhead). A filopodia contacts an AChR cluster (panel 4:00, asterisk) and then retracts (panel 4:10), contacts the cluster again (panel 4:20, asterisk), and persists until the end of the imaging session. Scale bar, $5 \mu \mathrm{m}$. D, Quantification of filopodial extension. The top panel illustrates a segment of a motor axon with three filopodia (green) and a prepatterned AChR cluster (red) off to the side of the axon. In the bottom panel, the dashed line indicates the shortest distance between the base of each filopodia at the axon and the AChR cluster. The solid line indicates the actual direction of filopodial extension. The angle between these two lines was measured for each filopodia. Scale bar, $5 \mu \mathrm{m}$. $\boldsymbol{E}$, Distribution of the angle of filopodial extension with respect to prepatterned AChR clusters for the RoP axon shown in $A-C$. The location of prepatterned AChR clusters was aligned at $0^{\circ}$ (red dot). Each line represents one filopodia, the length of the line represents filopodial length, and the angle represents the angle of filopodial extension with respect to a prepatterned $A C h R$ cluster. The majority of filopodia are extended at an angle $\leq 30^{\circ}$ with respect to prepatterned $A C h R$ clusters. $\boldsymbol{F}$, Distribution of the angle of filopodial extension with respect to a control area $15 \mu \mathrm{m}$ away from the axon. Filopodia are extended randomly if an AChR cluster is not present. $\mathbf{G}$, Summary plot of cumulative percent of angles of filopodial extension with respect to prepatterned AChR clusters (gray line; $n=622-30$ hpf embryos, 6 motor neurons, 230 filopodia) or control areas (black line; $n=167$ filopodia) for all filopodia from all motor neurons imaged (asterisk indicates significant difference, Kolmogorov-Smirnov test, $p<0.0001$ ). 

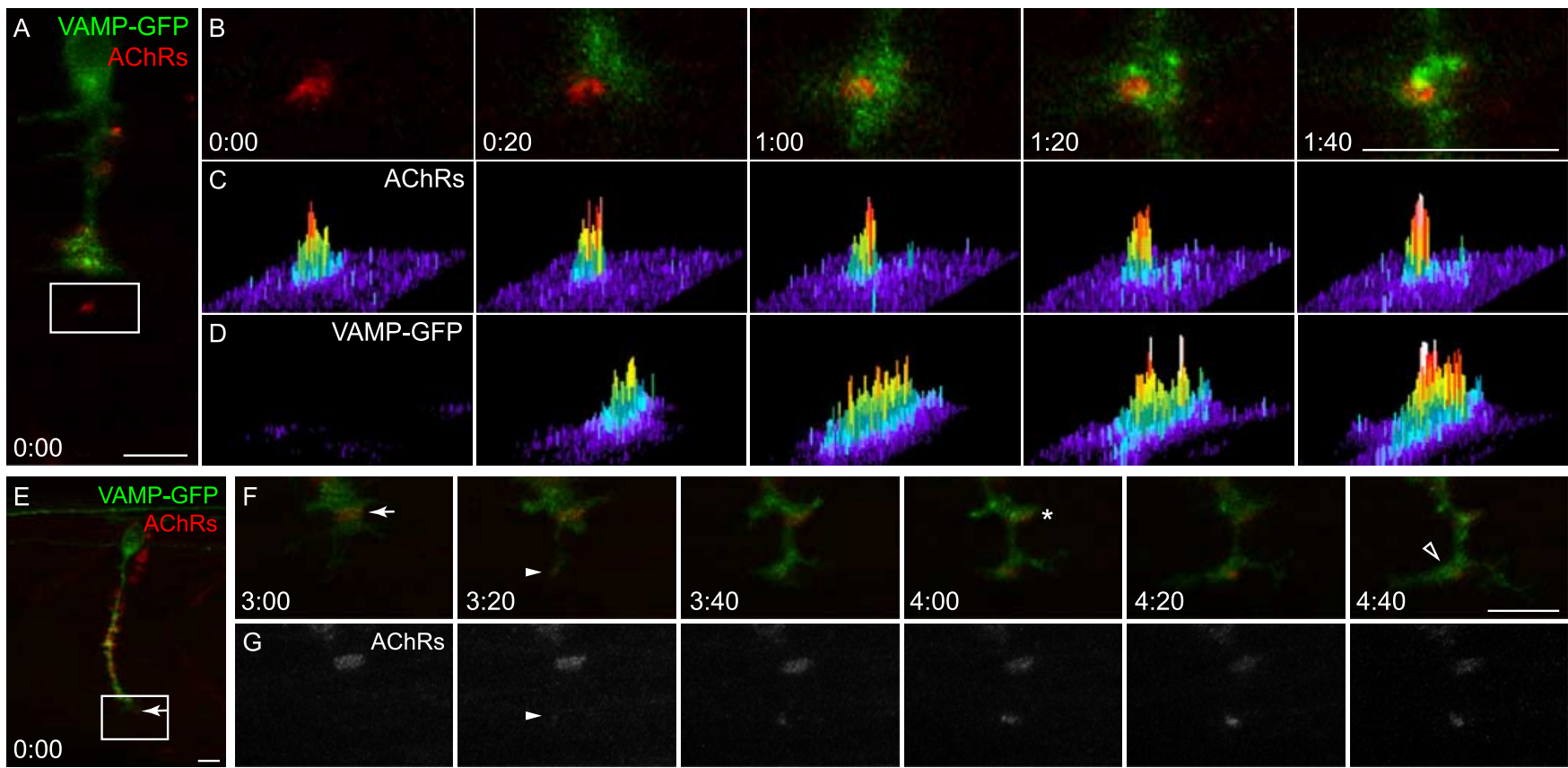

Figure 6. Postsynaptic AChR clusters precede presynaptic vesicle clusters during initial neuromuscular synaptogenesis. Primary motor neurons (CaP) expressing VAMP-GFP (green) and prepatterned AChR clusters labeled with rhodamine $\alpha \mathrm{BTX}$ (red) from a $\sim 24 \mathrm{hpf}$ embryos imaged for $2-5 \mathrm{~h}$ at intervals of 20 min. $\boldsymbol{A}$, At the beginning of the imaging session, a prepatterned AChR cluster is present in advance of the growth cone. The boxed region is shown at higher magnification in $\boldsymbol{B}$. Scale bar, $10 \mu \mathrm{m}$. $\boldsymbol{B}$, Time-lapse images of the growth cone extending toward, contacting, and then extending beyond the AChR cluster. In panels 1:20 and 1:40, clusters of VAMP-GFP+ vesicles have accumulated over the AChR cluster. Scale bar, $10 \mu \mathrm{m}$. $\boldsymbol{C}, \boldsymbol{D}$, The fluorescence intensity of postsynaptic AChRs $(\boldsymbol{C})$ and presynaptic VAMP-GFP $(\boldsymbol{D})$ are displayed as bars, the height and color of which are proportional to intensity (white, high; purple, low). This analysis shows that VAMP-GFP gradually accumulates over the AChR cluster. $\boldsymbol{E}$, At the beginning of the imaging session, a prepatterned AChR cluster is present in advance of the growth cone (arrow). The boxed region is shown at higher magnification in $\boldsymbol{F}$ and $\mathbf{G}$. Scale bar, $10 \mu \mathrm{m} . \boldsymbol{F}, \mathbf{G}$, Time-lapse images of the growth cone contacting and growing past a prepatterned AChR cluster and the subsequent appearance of an AChR cluster beneath a filopodia. AChR labeling alone is shown in $\mathbf{G}$ for clarity. The cluster that was present in advance of the growth cone is marked in $\boldsymbol{F}$, panel 3:00, with an arrow. A VAMP-GFP + cluster is subsequently induced over this AChR cluster (panel 4:00, asterisk). In addition, a cluster subsequently appears beneath a filopodia ( $\boldsymbol{F}, \mathbf{G}$, panel 3:20, arrowhead). This AChR cluster becomes larger and increases in intensity over time (G, panel 4:40). A VAMP-GFP+ cluster appears at this site (panel 3:40) and persists throughout the imaging period ( $\boldsymbol{F}$, panel 4:40, open arrowhead). Scale bar, $10 \mu \mathrm{m}$.

ing of presynaptic vesicles does not require AChR activity or protein. Thus, although work in zebrafish (Zhang et al., 2004) and mice (Lin et al., 2001; Yang et al., 2001) shows that MuSK is required for the formation of prepatterned AChR clusters, cellcell signals that are colocalized with prepatterned AChR clusters mediate initial neuromuscular synaptogenesis.

\section{Formation and fate of prepatterned AChR clusters}

Our previous observations in zebrafish embryos showed that initially diffuse, elongated prepatterned AChR clusters are present throughout the myotome before motor axon outgrowth from the spinal cord (Panzer et al., 2005). The mechanism by which AChRs are clustered in the absence of innervation has been the subject of much speculation. Prepatterned AChR clusters are able to form in mice lacking motor neurons and thus muscle fiber innervation, as well as in mice lacking agrin, but do not form in mice lacking MuSK or rapsyn (Lin et al., 2001; Burden, 2002). Thus, MuSK signaling may be activated independently of agrin, perhaps by an alternate, muscle-derived ligand, to establish prepatterned AChRs. Alternatively, sufficient MuSK activation that leads to the formation of prepatterned AChR clusters might not require ligand binding. In the absence of agrin, MuSK is active at low levels (Gillespie et al., 1996; Apel et al., 1997; Watty et al., 2000) and activated MuSK can recruit and cluster additional MuSK molecules (Jones et al., 1999). Thus, prepatterned AChR clusters may be formed by early expression and activation of MuSK in muscle fibers.

Initially diffuse prepatterned AChR clusters then coalesce and become more punctate. Some clusters are innervated, whereas others are not. Many of the uninnervated AChR clusters disappear, whereas others persist for at least several hours. Interestingly, all neuromuscular synapses present at the completion of motor axon outgrowth across the myotome contain AChRs that can be labeled at the time of the original prepattern. This result suggests that AChRs from dispersed clusters may, in fact, be redistributed and eventually incorporated into newly formed synapses. It is unclear why many uninnervated AChR clusters are dispersed, whereas others persist uninnervated for at least several hours. Previous studies have suggested that prepatterned clusters are dispersed in a neuron- and activity-dependent manner, and that AChRs are subsequently reclustered beneath nascent motor nerve terminals via agrin-MuSK signaling (Misgeld et al., 2002; Brandon et al., 2003). In mice, AChR clusters are larger and more numerous in the absence of motor axons or in the absence of motor axons and agrin (Yang et al., 2001), compared with the absence of agrin alone (Lin et al., 2001, 2005). This suggests that axons may provide signals that disperse AChR clusters that are not stabilized by agrin (Lin et al., 2001, 2005; Yang et al., 2001; Misgeld et al., 2005). One such signal has been proposed to be presynaptic ACh release. In mutant mice lacking choline acetyltransferase and thus ACh release, neuromuscular synapses are distributed over a wider region of the muscle compared with wild-type littermates (Misgeld et al., 2002; Brandon et al., 2003). This suggests that ACh release may lead to the dispersion of prepatterned AChR clusters. In recent work in which neuromuscular synapses were examined in mutant mice lacking agrin and 
choline acetyltransferase, synapses formed normally in the absence of agrin and ACh release. This suggested that ACh destabilizes postsynaptic AChR clusters, and that agrin counteracts this action, functioning as an anti-declustering signal. (Misgeld et al., 2005) (see also Lin et al., 2005). However, our results show that, in zebrafish, AChR blockade with $\alpha$ BTX does not affect prepatterned AChR cluster number, size, or incorporation into synapses. In addition, blockade of activity with tricaine or TTX does not affect overall neuromuscular synaptogenesis. Thus, although presynaptic synthesis of ACh has been shown to be necessary for normal neuromuscular synapse formation in mice (Misgeld et al., 2002, 2005; Brandon et al., 2003; Lin et al., 2005), AChR-mediated signaling and activity may not be essential for these early events in zebrafish.

\section{Motor axon growth cones and filopodia preferentially contact prepatterned \\ AChR clusters}

Previous work in vitro showed that motor axon growth cones do not preferentially contact preexisting AChR clusters, but rather these are dispersed and new clusters are induced (Anderson and Cohen, 1977; Frank and Fischbach, 1979). We observed that motor axon growth cones and filopodia are preferentially extended toward prepatterned receptor clusters, demonstrating that the initial contact between motor axon growth cones and prepatterned receptor clusters is not random. Our observations further show that such receptor clusters are targeted by motor axons for subsequent synapse formation, because presynaptic synaptic vesicle clusters subsequently formed over prepatterned AChR clusters. Because motor axon growth cones have been shown to release ACh in vivo (Hume et al., 1983), the fact that presynaptic terminals are formed over prepatterned AChR clusters would allow for synaptic transmission to begin rapidly after presynaptic and postsynaptic contact.

Our results show that motor axon outgrowth and neuromuscular synaptogenesis are not altered when AChRs are blocked or absent. This suggests that signaling through postsynaptic AChRs is not required for these events to occur. Similar results have been obtained in nic-1 mutant zebrafish that lack AChRs (Westerfield et al., 1990) and in twitch once mutants in which rapsyn is defective and AChRs do not cluster (Ono et al., 2002). It seems likely that other cues are necessary to attract motor axon growth cones and filopodia, and our data suggest that such cues are patterned appropriately in the absence of AChR activity and in the complete absence of AChR clusters. One obvious candidate is MuSK or a downstream signaling component. In mouse, MuSK has been shown to be colocalized with prepatterned AChR clusters
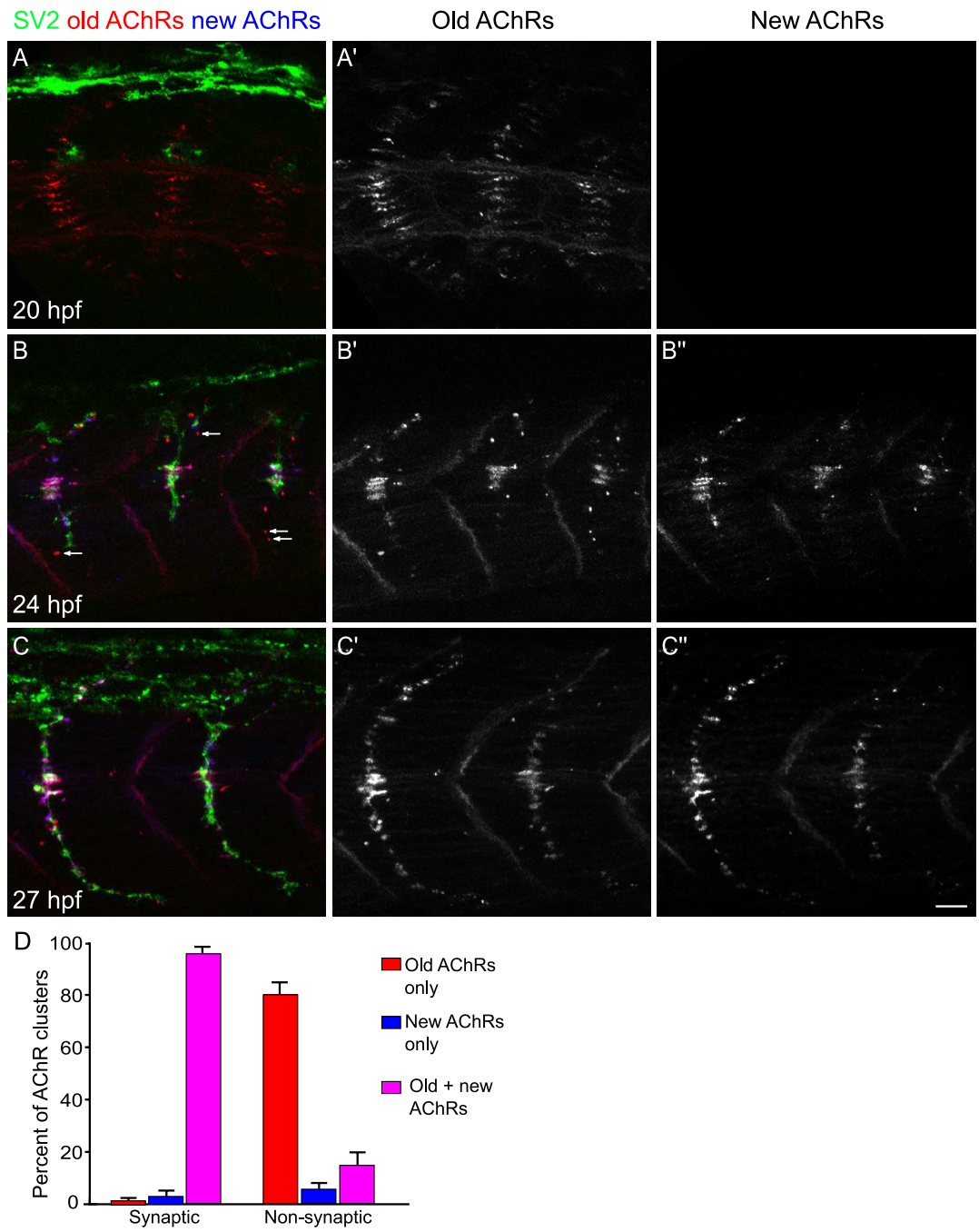

Figure 7. Insertion of new AChRs and redistribution of prepatterned AChRs during initial neuromuscular synaptogenesis. All AChRs were optically saturated with rhodamine $\alpha$ BTX at $20 \mathrm{hpf}$, and 2, 4, or $7 \mathrm{~h}$ later, embryos were fixed and newly inserted AChRs , $\boldsymbol{A}-\boldsymbol{A}^{\prime}$, Prepatterned $\mathrm{AChRs}$ present before motor axon outgrowth at $20 \mathrm{hpf}$. $\boldsymbol{B}-\boldsymbol{B}^{\prime \prime}$, In embryos relabeled with Cy5 $\alpha$ BTX

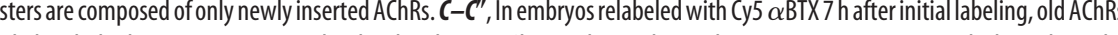
receptors in synaptic and nonsynaptic sites ( $n=622-24 \mathrm{hpf}$ embryos, 170 clusters). Error bars indicate SE.

(Burden, 2002), and defects in motor axon outgrowth, branching, and initial neuromuscular synaptogenesis are observed in MuSK mutant mice (Sanes and Lichtman, 1999) and in unplugged mutant zebrafish in which the zebrafish MuSK homolog is absent (Zhang et al., 2004). Alternatively, motor axon pathfinding might not require MuSK itself, but rather one of the many signaling components downstream of MuSK activation.

One might also argue that motor axon pathfinding is preprogrammed and that the muscle prepatterning reported here might simply be coincident with the future path of motor axons, but neither critical nor instructive. Given the precise contacts we observe between motor axon growth cones, their filopodia, and prepatterned AChR clusters, we feel that this explanation is highly unlikely. In addition, work from several groups supports 

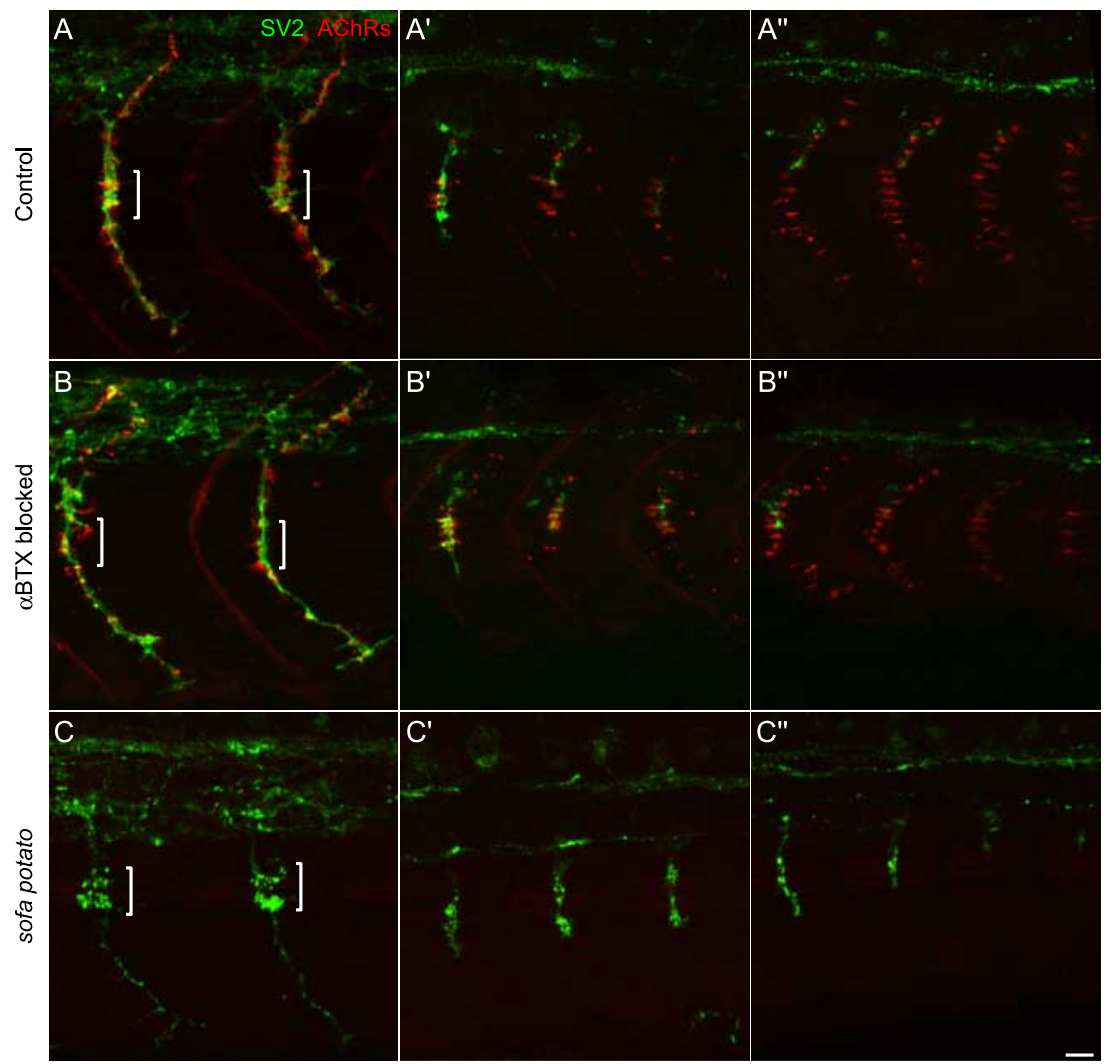

D

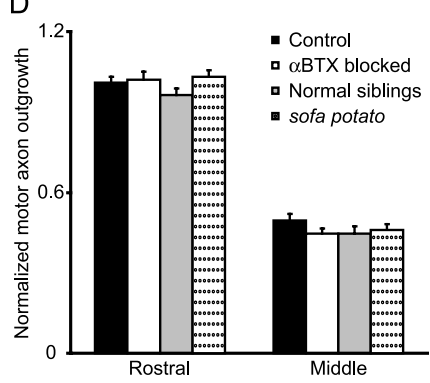

E
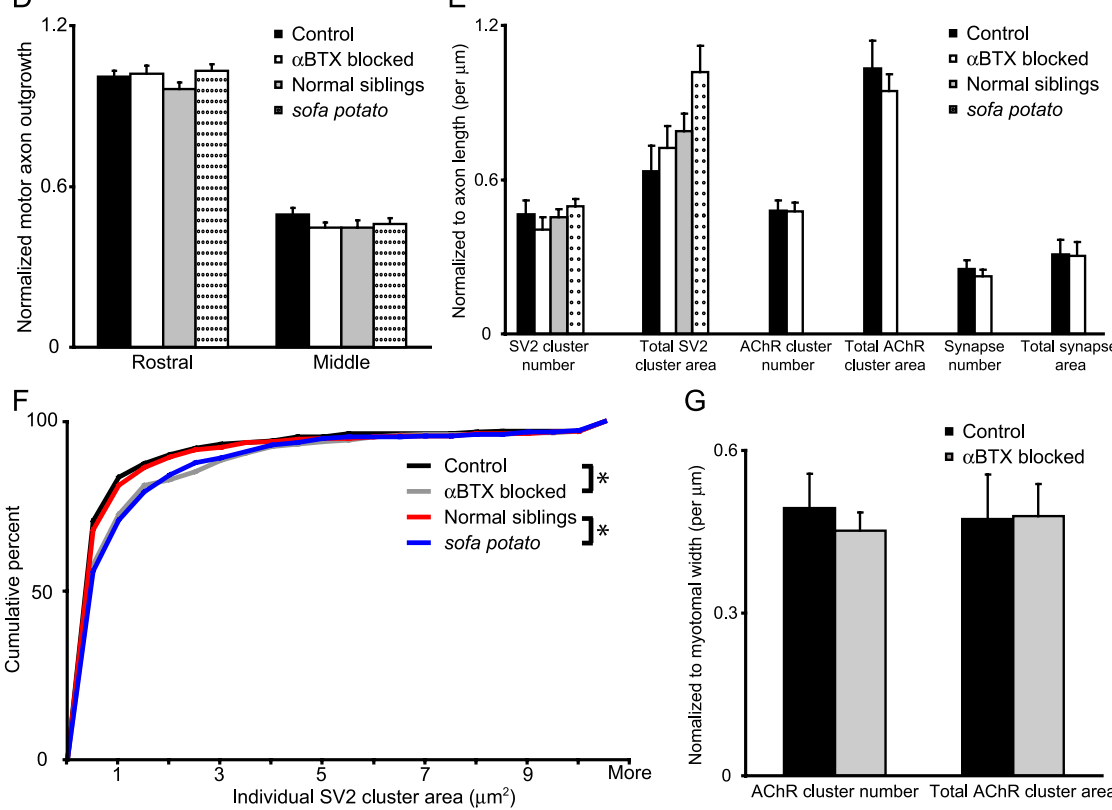

G

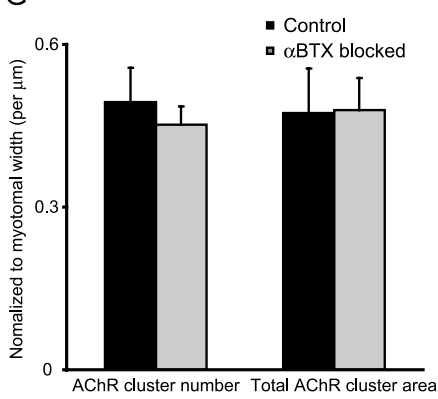

Figure 8. AChR activity or AChR clusters are not required for motor axon outgrowth or neuromuscular synaptogenesis. $A-C$ Embryos (24 hpf) in which SV2 + presynaptic axons and terminals (green) and rhodamine $\alpha$ BTX labeled AChRs (red) were analyzed in rostral $(\boldsymbol{A}, \boldsymbol{B}, \boldsymbol{C})$, middle $\left(\boldsymbol{A}^{\prime}, \boldsymbol{B}^{\prime}, \boldsymbol{C}^{\prime}\right)$, and caudal $\left(\boldsymbol{A}^{\prime \prime}, \boldsymbol{B}^{\prime \prime}, \boldsymbol{C}^{\prime \prime}\right)$ segments. Brackets indicate the location of the first neuromuscular synapses formed at the choice point. $A$, Motor axon outgrowth, prepatterned AChRs, and initial neuromuscular synaptogenesis in wild-type, unmanipulated control embryos ( $n=424 \mathrm{hpf}$ embryos, 8 myotome segments). $\boldsymbol{B}$, Motor axon outgrowth, prepatterned AChRs, and initial neuromuscular synaptogenesis in embryos in which AChRs were blocked with rhodamine $\alpha \mathrm{BTX}$ from 12 to $24 \mathrm{hpf}$ ( $n=424 \mathrm{hpf}$ embryos, 8 myotome segments). The dorsal and ventral extent of motor axon outgrowth, prepatterned AChRs, and initial synaptogenesis are similar to control embryos. C, Motor axon outgrowth and formation of SV2 + presynaptic vesicle clusters in sop embryos ( $n=724$ hpf embryos, 14 myotome segments). Although AChRs are absent, the dorsal and ventral extent of motor axon outgrowth is similar to normal siblings ( $n=624 \mathrm{hpf}$ embryos, 12 myotome segments) (data not shown). Presynaptic vesicle clusters are present all along the length of axons, but clusters at the choice point (bracket) are enlarged. Scale bar, $10 \mu \mathrm{m} . \boldsymbol{D}$, Quantification of motor axon outgrowth, normalized to myotome width, for rostral and middle myotomes in control and $\alpha \mathrm{BTX}$-blocked embryos, sop mutants, and normal siblings. Mean values \pm SEM are not significantly different (Student's $t$ test). E, Quantification of SV2 + cluster number and total area in control and $\alpha$ BTX-blocked the existence of prepatterned cues in muscle fibers that instruct motor axon pathfinding decisions (Zeller et al., 2002; Zhang et al., 2004). The striking pathfinding abnormalities in the zebrafish un plugged mutant further support the idea that signaling molecules copatterned with AChR clusters might play a key role in shaping the innervation of myotomal muscles (Zhang et al., 2004).

\section{Temporal order of synapse assembly}

The temporal order of presynaptic and postsynaptic differentiation during synaptogenesis has been the subject of much debate, primarily because, to date, the imaging analyses required to definitively address these questions have not been performed in vivo. In zebrafish, previous time-lapse observations in vivo have suggested that AChRs are clustered after motor axon contact, but these data have limited optical and temporal resolution (Liu and Westerfield, 1992). There is no evidence that motor axons extend into the myotome, induce AChR clusters, and then retract, growing out again at later times (Liu and Westerfield, 1992; Zhang et al., 2004; Flanagan-Steet et al., 2005). Although we do observe rare instances in which motor axon filopodia appear to induce AChR clusters, these represent a small minority of initial neuromuscular synapse formation events. This remains true even when the dynamics of this process are examined at finer temporal resolution than reported here (Y. Song, J. Panzer, and R. Balice-Gordon, unpublished observations). Thus, it seems unlikely that axons or filopodia that might initially induce AChR clusters were underestimated.

embryos, sop mutants, and normal siblings, and of AChR cluster and synapse number and total area in control and $\alpha \mathrm{BTX}$ blocked embryos. Number and total area measurements were normalized to axon length. Mean values \pm SEM are not significantly different between control and $\alpha \mathrm{BTX}$-blocked embryos or between sop mutants and normal siblings (Student's $t$ test). $\boldsymbol{F}$, (umulative percentage of the area of individual SV2 + clusters in control and $\alpha$ BTX-blocked embryos, sop mutants, and normal siblings. Although the mean values for total area are not different among these groups $(\boldsymbol{E})$, the distribution of the area of individual SV2 + clusters is shifted toward larger values in $\alpha$ BTX-blocked compared with control embryos (asterisks indicate significant differences, Kolmogorov-Smirnov test, $p=0.002$ ) and in sop mutants compared with normal siblings $(p<0.0001)$, probably reflecting the enlarged presynaptic SV2 + cluster area at three to four choice point synapses in each myotome. G, Quantification of prepatterned $A C h R$ cluster number and total area from caudal segments of control and $\alpha$ BTX-blocked embryos, normalized to myotome width. Mean values \pm SEM are not significantly different (Student's $t$ test). 
Rather, our data indicate that postsynaptic muscle fibers, by virtue of the existence of cues prepatterned with AChR clusters, determine the spatial location of initial synapses, and that postsynaptic AChR clustering temporally precedes synaptic vesicle clustering during initial synaptogenesis. It is likely that the accumulation of synaptic vesicles over AChR clusters represents the formation of a functional synapse, because motor axon growth cones containing synaptic vesicles have been shown to release ACh in vivo (Hume et al., 1983). Future studies are required to confirm active vesicle cycling at these early synapses using, for example, genetically encoded markers of exocytosis, and to determine the order of accumulation of other additional synaptic components presynaptically and postsynaptically.

Although AChR clustering temporally precedes synaptic vesicle clustering during initial synaptogenesis, at later stages of synaptogenesis, presynaptic axons probably also induce additional postsynaptic AChR clusters, because the total number of neuromuscular synapses present at $72 \mathrm{hpf}$ is larger than the number of prepatterned AChR clusters initially present. Thus, there may be two distinct modes of synaptogenesis. In the first mode, initial synapses are formed at sites that contain preexisting neurotransmitter receptor clusters. In a second and possibly contemporaneous mode, additional synapses are formed by the clustering of receptors beneath presynaptic nerve terminals (Flanagan-Steet et al., 2005). In skeletal muscle, these latter events are mediated by agrin-MuSK and other signaling (Sanes and Lichtman, 1999). In the CNS, most studies in culture have indicated that presynaptic differentiation precedes and may initiate postsynaptic differentiation (Rao et al., 1998; Friedman et al., 2000; Okabe et al., 2001; Washbourne et al., 2002; Bresler et al., 2004). Clearly, additional experiments are necessary in vitro as well as in vivo to resolve these issues in the CNS and to determine whether one or both modes of synapse formation do indeed occur. That prepatterning of postsynaptic targets plays a previously unappreciated and important role in neuromuscular synaptogenesis suggests that this process may also be important during CNS synaptogenesis and thus be a general mechanism that shapes neural circuitry during development.

\section{References}

Anderson MJ, Cohen MW (1977) Nerve-induced and spontaneous redistribution of acetylcholine receptors on cultured muscle cells. J Physiol (Lond) 268:757-773.

Aoki C, Venkatesan C, Go CG, Mong JA, Dawson TM (1994) Cellular and subcellular localization of NMDA-R1 subunit immunoreactivity in the visual cortex of adult and neonatal rats. J Neurosci 14:5202-5222.

Apel ED, Glass DJ, Moscoso LM, Yancopoulos GD, Sanes JR (1997) Rapsyn is required for MuSK signaling and recruits synaptic components to a MuSK-containing scaffold. Neuron 18:623-635.

Arber S, Burden SJ, Harris AJ (2002) Patterning of skeletal muscle. Curr Opin Neurobiol 12:100-103.

Bloch RJ (1988) Molecular events in synaptogenesis: nerve-muscle adhesion and postsynaptic differentiation. Am J Physiol 254:C345-C364.

Brandon EP, Lin W, D'Amour KA, Pizzo DP, Dominguez B, Sugiura Y, Thode S, Ko CP, Thal LJ, Gage FH, Lee KF (2003) Aberrant patterning of neuromuscular synapses in choline acetyltransferase-deficient mice. J Neurosci 23:539-549.

Bresler T, Shapira M, Boeckers T, Dresbach T, Futter M, Garner CC, Rosenblum K, Gundelfinger ED, Ziv NE (2004) Postsynaptic density assembly is fundamentally different from presynaptic active zone assembly. J Neurosci 24:1507-1520.

Burden SJ (2002) Building the vertebrate neuromuscular synapse. J Neurobiol 53:501-511.

Cooper RL, Fernandez-de-Miguel F, Adams WB, Nicholls JG (1992) Anterograde and retrograde effects of synapse formation on calcium currents and neurite outgrowth in cultured leech neurons. Proc R Soc Lond B Biol Sci 249:217-222.
Eisen JS, Myers PZ, Westerfield M (1986) Pathway selection by growth cones of identified motoneurones in live zebra fish embryos. Nature 320:269-271.

Feng G, Laskowski MB, Feldheim DA, Wang H, Lewis R, Frisen J, Flanagan JG, Sanes JR (2000) Roles for ephrins in positionally selective synaptogenesis between motor neurons and muscle fibers. Neuron 25:295-306.

Fischbach GD, Cohen SA (1973) The distribution of acetylcholine sensitivity over uninnervated and innervated muscle fibers grown in cell culture. Dev Biol 31:147-162.

Flanagan-Steet H, Fox MA, Meyer D, Sanes JR (2005) Neuromuscular synapses can form in vivo by incorporation of initially aneural postsynaptic specializations. Development 132:4471-4481.

Frank E, Fischbach GD (1979) Early events in neuromuscular junction formation in vitro: induction of acetylcholine receptor clusters in the postsynaptic membrane and morphology of newly formed synapses. J Cell Biol 83:143-158.

Friedman HV, Bresler T, Garner CC, Ziv NE (2000) Assembly of new individual excitatory synapses: time course and temporal order of synaptic molecule recruitment. Neuron 27:57-69.

Gillespie SK, Balasubramanian S, Fung ET, Huganir RL (1996) Rapsyn clusters and activates the synapse-specific receptor tyrosine kinase MuSK. Neuron 16:953-962.

Goda Y, Davis GW (2003) Mechanisms of synapse assembly and disassembly. Neuron 40:243-264.

Harris AJ (1981) Embryonic growth and innervation of rat skeletal muscles. III. Neural regulation of junctional and extra-junctional acetylcholine receptor clusters. Phil Trans R Soc Lond B 293:287-314.

Hume RI, Role LW, Fischbach GD (1983) Acetylcholine release from growth cones detected with patches of acetylcholine receptor-rich membranes. Nature 305:632-634.

Javaherian A, Cline HT (2005) Coordinated motor neuron axon growth and neuromuscular synaptogenesis are promoted by CPG15 in vivo. Neuron 45:505-512.

Jin Y (2002) Synaptogenesis: insights from worm and fly. Curr Opin Neurobiol 12:71-79.

Jones G, Moore C, Hashemolhosseini S, Brenner HR (1999) Constitutively active MuSK is clustered in the absence of agrin and induces ectopic postsynaptic-like membranes in skeletal muscle fibers. J Neurosci 19:3376-3383.

Jontes JD, Emond MR, Smith SJ (2004) In vivo trafficking and targeting of $\mathrm{N}$-cadherin to nascent presynaptic terminals. J Neurosci 24:9027-9034.

Lefebvre JL, Ono F, Puglielli C, Seidner G, Franzini-Armstrong C, Brehm P, Granato M (2004) Increased neuromuscular activity causes axonal defects and muscular degeneration. Development 131:2605-2618.

Lin W, Burgess RW, Dominguez B, Pfaff SL, Sanes JR, Lee KF (2001) Distinct roles of nerve and muscle in postsynaptic differentiation of the neuromuscular synapse. Nature 410:1057-1064.

Lin W, Dominguez B, Yang J, Aryal P, Brandon EP, Gage FH, Lee KF (2005) Neurotransmitter acetylcholine negatively regulates neuromuscular synapse formation by a Cdk5-dependent mechanism. Neuron 46:569-579.

Liu DW, Westerfield M (1992) Clustering of muscle acetylcholine receptors requires motoneurons in live embryos, but not in cell culture. J Neurosci 12:1859-1866.

Lupa MT, Hall ZW (1989) Progressive restriction of synaptic vesicle protein to the nerve terminal during development of the neuromuscular junction. J Neurosci 9:3937-3945.

Misgeld T, Burgess RW, Lewis RM, Cunningham JM, Lichtman JW, Sanes JR (2002) Roles of neurotransmitter in synapse formation. Development of neuromuscular junction lacking choline acetyltransferase. Neuron 36:635-648.

Misgeld T, Kummer TT, Lichtman JW, Sanes JR (2005) Agrin promotes synaptic differentiation by counteracting an inhibitory effect of neurotransmitter. Proc Natl Acad Sci USA 102:11088-11093.

Morris JK, Lin W, Hauser C, Marchuk Y, Getman D, Lee KF (1999) Rescue of the cardiac defect in ErbB2 mutant mice reveals essential roles of ErbB2 in peripheral nervous system development. Neuron 23:273-283.

Myers PZ, Eisen JS, Westerfield M (1986) Development and axonal outgrowth of identified motoneurons in the zebrafish. J Neurosci 6:2278-2289.

Okabe S, Miwa A, Okado H (2001) Spine formation and correlated assembly of presynaptic and postsynaptic molecules. J Neurosci 21:6105-6114. Ono F, Higashijima S, Shcherbatko A, Fetcho JR, Brehm P (2001) Paralytic 
zebrafish lacking acetylcholine receptors fail to localize rapsyn clusters to the synapse. J Neurosci 21:5439-5448.

Ono F, Shcherbatko A, Higashijima S, Mandel G, Brehm P (2002) The zebrafish motility mutant twitch once reveals new roles for rapsyn in synaptic function. J Neurosci 22:6491-6498.

Panzer JA, Gibbs SM, Dosch R, Wagner D, Mullins MC, Granato M, BaliceGordon RJ (2005) Neuromuscular synaptogenesis in wild-type and mutant zebrafish. Dev Biol 285:340-357.

Park HC, Kim CH, Bae YK, Yeo SY, Kim SH, Hong SK, Shin J, Yoo KW, Hibi M, Hirano T, Miki N, Chitnis AB, Huh TL (2000) Analysis of upstream elements in the $\mathrm{HuC}$ promoter leads to the establishment of transgenic zebrafish with fluorescent neurons. Dev Biol 227:279-293.

Rao A, Kim E, Sheng M, Craig AM (1998) Heterogeneity in the molecular composition of excitatory postsynaptic sites during development of hippocampal neurons in culture. J Neurosci 18:1217-1229.

Sabo SL, McAllister AK (2003) Mobility and cycling of synaptic proteincontaining vesicles in axonal growth cone filopodia. Nat Neurosci 6:1264-1269.

Saito Y, Murakami F, Song WJ, Okawa K, Shimono K, Katsumaru H (1992) Developing corticorubral axons of the cat form synapses on filopodial dendritic protrusions. Neurosci Lett 147:81-84.

Sanes JR, Lichtman JW (1999) Development of the vertebrate neuromuscular junction. Annu Rev Neurosci 22:389-442.

Sytkowski AJ, Vogel Z, Nirenberg MW (1973) Development of acetylcho- line receptor clusters on cultured muscle cells. Proc Natl Acad Sci USA 70:270-274.

Washbourne P, Bennett JE, McAllister AK (2002) Rapid recruitment of NMDA receptor transport packets to nascent synapses. Nat Neurosci 5:751-759.

Watty A, Neubauer G, Dreger M, Zimmer M, Wilm M, Burden SJ (2000) The in vitro and in vivo phosphotyrosine map of activated MuSK. Proc Natl Acad Sci USA 97:4585-4590.

Westerfield M, McMurray JV, Eisen JS (1986) Identified motoneurons and their innervation of axial muscles in the zebrafish. J Neurosci 6:2267-2277.

Westerfield M, Liu DW, Kimmel CB, Walker C (1990) Pathfinding and synapse formation in a zebrafish mutant lacking functional acetylcholine receptors. Neuron 4:867-874.

Yang X, Li W, Prescott ED, Burden SJ, Wang JC (2000) DNA topoisomerase IIbeta and neural development. Science 287:131-134.

Yang X, Arber S, William C, Li L, Tanabe Y, Jessell TM, Birchmeier C, Burden SJ (2001) Patterning of muscle acetylcholine receptor gene expression in the absence of motor innervation. Neuron 30:399-410.

Zeller J, Schneider V, Malayaman S, Higashijima S, Okamoto H, Gui J, Lin S, Granato M (2002) Migration of zebrafish spinal motor nerves into the periphery requires multiple myotome-derived cues. Dev Biol 252:241-256.

Zhang J, Lefebvre JL, Zhao S, Granato M (2004) Zebrafish unplugged reveals a role for muscle-specific kinase homologs in axonal pathway choice. Nat Neurosci 7:1303-1309. 